\title{
Dynamic regulation of histone modifications and long-range chromosomal interactions during postmitotic transcriptional reactivation
}

\author{
Hyeseon Kang, ${ }_{1}^{1}$ Maxim N. Shokhirev, ${ }^{2}$ Zhichao Xu, ${ }^{3}$ Sahaana Chandran, ${ }^{3}$ Jesse R. Dixon, ${ }^{3}$ \\ and Martin W. Hetzer ${ }^{1}$ \\ ${ }^{1}$ Molecular and Cell Biology Laboratory, Salk Institute for Biological Studies, La Jolla, California 92037, USA; ${ }^{2}$ The Razavi Newman \\ Integrative Genomics and Bioinformatics Core (IGC), Salk Institute for Biological Studies, 92037 La Jolla, California, USA; ${ }^{3}$ Peptide \\ Biology Laboratory, Salk Institute for Biological Studies, La Jolla, California 92037, USA
}

During mitosis, transcription of genomic DNA is dramatically reduced, before it is reactivated during nuclear reformation in anaphase/telophase. Many aspects of the underlying principles that mediate transcriptional memory and reactivation in the daughter cells remain unclear. Here, we used ChIP-seq on synchronized cells at different stages after mitosis to generate genome-wide maps of histone modifications. Combined with EU-RNA-seq and Hi-C analyses, we found that during prometaphase, promoters, enhancers, and insulators retain H3K4me3 and H3K4me1, while losing H3K27ac. Enhancers globally retaining mitotic H3K4me1 or locally retaining mitotic H3K27ac are associated with cell type-specific genes and their transcription factors for rapid transcriptional activation. As cells exit mitosis, promoters regain $\mathrm{H} 3 \mathrm{~K} 27 \mathrm{ac}$, which correlates with transcriptional reactivation. Insulators also gain H3K27ac and CCCTC-binding factor (CTCF) in anaphase/telophase. This increase of H3K27ac in anaphase/telophase is required for posttranscriptional activation and may play a role in the establishment of topologically associating domains (TADs). Together, our results suggest that the genome is reorganized in a sequential order, in which histone methylations occur first in prometaphase, histone acetylation, and CTCF in anaphase/telophase, transcription in cytokinesis, and long-range chromatin interactions in early G1. We thus provide insights into the histone modification landscape that allows faithful reestablishment of the transcriptional program and TADs during cell division.

[Keywords: chromatin; mitosis; transcription]

Supplemental material is available for this article.

Received December 4, 2019; revised version accepted April 28, 2020.

Mitosis marks a dramatic transition during which cells move from a transcriptionally active to a largely repressed state in which most genes are transcriptionally inactive (Prescott and Bender 1962). This drastic reduction in transcriptional activity is associated with chromosome condensation (Vagnarelli 2013), loss of long-range DNA interactions (Naumova et al. 2013; Dileep et al. 2015; Gibcus et al. 2018), and exclusion of RNA polymerase II (Pol II) and most transcription factors (TFs) from chromatin (Gottesfeld and Forbes 1997). As cells exit mitosis and reform the nuclear envelope (NE), the transcriptional program is faithfully reactivated (Prasanth et al. 2003). This raises the important question of how the two daughter cells retain the memory of a defined gene expression pro-

Corresponding author: hetzer@salk.edu

Article published online ahead of print. Article and publication date are online at http://www.genesdev.org/cgi/doi/10.1101/gad.335794.119. Freely available online through the Genes \& Development Open Access option. gram. Recent work has shown that a selective gene transcription program is maintained throughout mitosis (Palozola et al. 2017). However, how transcription is reactivated during mitotic exit and the underlying molecular mechanisms that control transcriptional memory remain poorly understood.

Several features of interphase chromatin landscapes remain associated with mitotic chromatin and have been proposed to function as "bookmarks" of transcriptional programs during mitosis. These "bookmarks" include retention of chromatin accessibility (Martínez-Balbás et al. 1995; Hsiung et al. 2015; Teves et al. 2016; Oomen et al. 2019), multiple general and lineage-specific TFs (Young et al. 2007; Kadauke et al. 2012; Caravaca et al. 2013; Deluz et al. 2016; Festuccia et al. 2016; Teves et al. 2016), and certain histone modifications (Kouskouti and

(c) 2020 Kang et al. This article, published in Genes \& Development, is available under a Creative Commons License (Attribution 4.0 International), as described at http://creativecommons.org/licenses/by/4.0/. 
Talianidis 2005; Valls et al. 2005; Muramoto et al. 2010; Zhao et al. 2011). Specific histone modification patterns can define distinct chromatin states of cis-regulatory elements (cis-REs), such as promoters and enhancers, and regulate gene expression via interaction with transcription factors. H3K4me3 and H3K27ac are highly enriched at active promoters near the transcription start site (TSS) and positively correlated with transcription. Enhancers play a crucial role in the activation and fine-tuning of their target promoters. Enhancer elements can exist in two major chromatin states, primed or active. Primed enhancers (PEs) are marked by H3K4mel/2 and their target genes are weakly or not expressed, whereas active enhancers (AEs) are additionally marked by the histone acetyltransferases CBP/p300-mediated H3K27ac and are associated with actively transcribed genes (Heintzman et al. 2007; Creyghton et al. 2010; Calo and Wysocka 2013). Recently, chromatin immunoprecipitation sequencing (ChIP-seq) studies revealed spatial genomic information of active histone marks, including H3K4me1/3, H3K9ac, or H3K27ac at prometaphase-arrested cells (Liang et al. 2015; Liu et al. 2017; Javasky et al. 2018). These studies allowed the comparison between mitotic and interphase histone marks and revealed specific modifications, dynamics of chromatin states at cis-REs, and estimation of TF binding that could serve as bookmarks. Although specific histone modifications remain associated with mitotic chromatin even at reduced levels, it remains unclear whether such association on mitotic chromatin has a regulatory role in transcriptional activation during or after mitosis. Furthermore, it remains to be determined whether histone modifications, retained either at promoters or enhancers, contribute as bookmarks of transcriptional program during mitosis.

Genome-wide chromosome conformation capture data, such as that generated by the Hi-C method, can reveal that the structural features of interphase chromosomes, such as A and B compartments, topologically associating domains (TADs), and DNA loops are lost during prometaphase and reestablished in G1 phase (Naumova et al. 2013; Abramo et al. 2019). TADs are thought of as important basic units of chromosome organization and are demarcated from each other by boundaries (Dixon et al. 2012; Nora et al. 2012). However, what mediates TAD formation after mitosis remains poorly understood. TAD boundaries in interphase have been shown to be enriched in active transcription, housekeeping genes, tRNA genes and short interspersed nuclear elements (SINEs), as well as binding sites for the architectural proteins CCCTC-binding factor (CTCF) and cohesin complex (Dixon et al. 2012). Furthermore, targeted degradation of CTCF, using the auxin-induced rapid degradation system, resulted in the almost complete elimination of TADs, suggesting CTCF's essential role for the establishment of TADs (Nora et al. 2017). It is currently unclear whether CTCF or other features enriched at the boundaries in interphase chromatin are also involved in the reestablishment of TADs after mitosis.

In this study, we combined histone modification ChIPseq, EU-RNA-seq, and Hi-C from prometaphase to G1 phase to comprehensively examine on a genome-wide lev- el the temporal relationship between histone modification binding, nascent transcription, and long-range chromatin interactions during the mitosis-G1 transition. We found that H3K4me3 remains associated with almost all promoters and that $\mathrm{H} 3 \mathrm{~K} 4 \mathrm{mel}$ is highly retained at enhancers of cell type-specific genes during prometaphase. In contrast, H3K27ac is largely reduced during prometaphase, although a subset of $\mathrm{H} 3 \mathrm{~K} 27 \mathrm{ac}$ remains at enhancers of cell type-specific genes and promotes early expression of these cell type-specific genes. During the anaphase/telophase transition, most promoters gain $\mathrm{H} 3 \mathrm{~K} 27 \mathrm{ac}$, and this is essential for the accurate transmission of gene expression programs during cell division. Furthermore, TAD boundaries during prometaphase remain associated with $\mathrm{H} 3 \mathrm{~K} 4 \mathrm{me} 3$ and $\mathrm{H} 3 \mathrm{~K} 4 \mathrm{mel}$ in the absence of CTCF, but CTCF is recruited and enriched at the boundaries during anaphase/telophase together with H3K27ac before the appearance of loops, TADs, and compartments. Altogether, the multilevel data of epigenetic landscape, nascent transcription, and TAD interaction shed light on not only the temporal order of genome organization after mitosis but also indicate a potential bookmarking role for histone modifications in accurate reestablishment of transcriptional activation pattern and long-range chromatin interactions.

\section{Results}

H3K27ac is lost in prometaphase and regained in anaphase/telophase

Transcription is reactivated at the time of mitotic exit, as the NE starts reassembling and RNA Pol II globally rebinds to the chromatin (Prasanth et al. 2003). It is thus important to study this stage to fully understand genome organization during cell division. To determine the relationship between epigenetic dynamics, gene expression, and long-range chromatin interactions at the mitosisG1 transition, we used three independent methods: (1) ChIP-seq analysis to identify genome localization mapping of key histone modifications, (2) EU-RNA-seq to capture temporal nascent transcription expression, and (3) Hi$\mathrm{C}$ to determine the timing of long-range chromatin interactions from prometaphase to G1 phase (Fig. 1A). In order to obtain cells at different cell cycle stages including mitotic exit, we synchronized two human cell lines, osteosarcoma U2OS and retina pigment epithelia RPE1 cells using thymidine and nocodazole. The degree of synchrony at each cell cycle stage was monitored by fluorescence microscopy of Hoechst and a-Tubulin stained cells. Asynchronous populations (interphase) had $<2 \%$ mitotic cells, nocodazole-arrested culture (prometaphase) contained $>95 \%$ mitotic cells, and cells released from nocodazole-induced arrest for $35 \mathrm{~min}$ (anaphase/telophase) were $\sim 70 \%$ enriched for anaphase/telophase (Supplemental Fig. S1A). Thus, our synchronization approach enables us to collect enriched populations of cells at prometaphase, anaphase/telophase, and interphase, respectively.

To determine the mitotic retention of histone modifications in our system, we focused on three histone 
Downloaded from genesdev.cshlp.org on April 26, 2023 - Published by Cold Spring Harbor Laboratory Press

Reactivation of transcription after mitosis

A

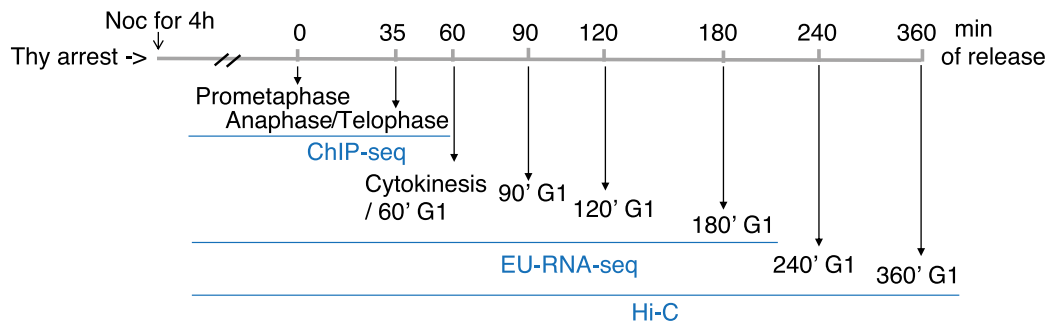

B

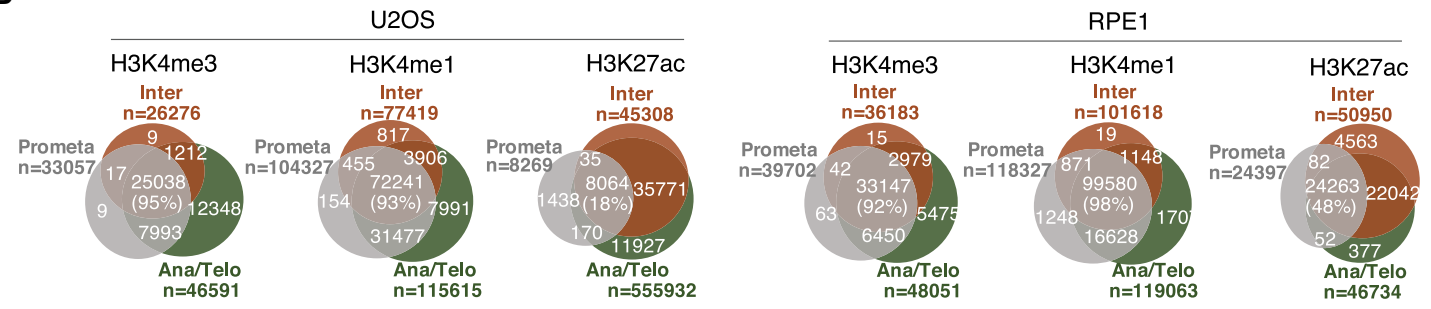

C

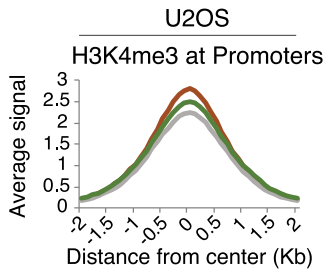

RPE1

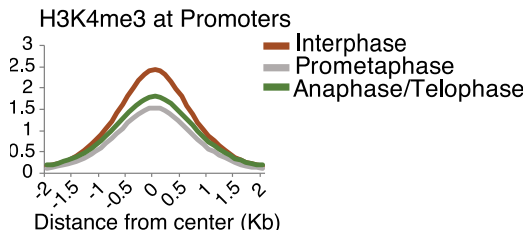

D
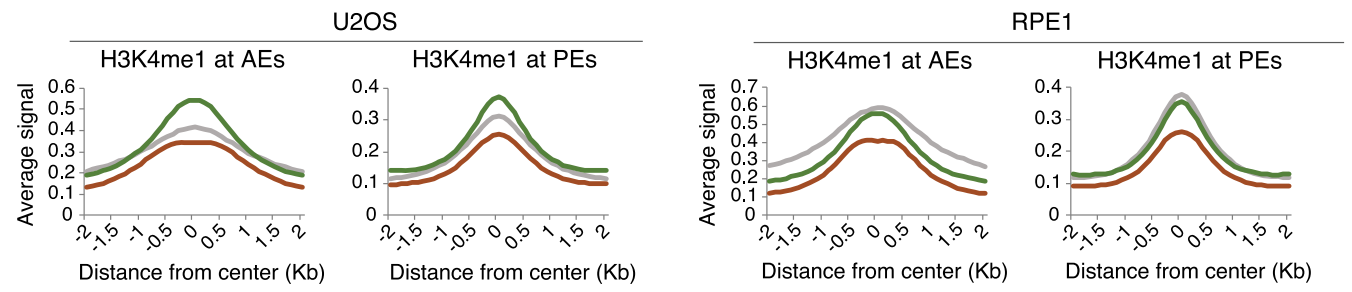

$\mathbf{E}$
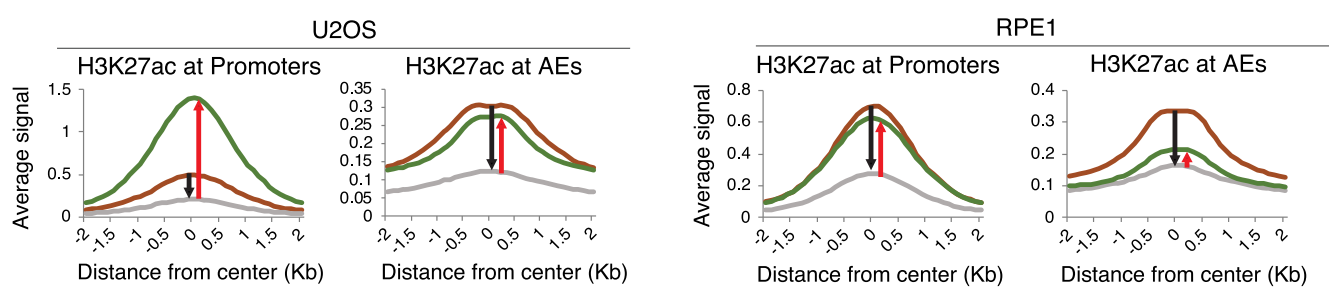

Figure 1. Cell cycle-dependent regulation of H3K27ac. (A) Schematic of the experimental strategy combining ChIP-seq, EU-RNA-seq, and $\mathrm{Hi}-\mathrm{C}$ during prometaphase, anaphase/telophase, and various G1 phases. Mitotic cells were obtained by thymidine and nocodazole treatments. Anaphase/Telophase and G1 phase cells were obtained after release from mitotic arrest for indicated time. $(B)$ Venn diagram showing the number of H3K4me3, H3K4me1, and H3K27ac binding sites that were found in interphase (Inter, orange), prometaphase (Prometa, gray), and anaphase/telophase (Ana/Telo, green) in U2OS (left panel) and RPE1 (right panel) cells. n represents the number of observed histone modification peaks in each cell cycle phase. Percentage of interphase peaks that were also detected in mitotic cells are shown. $(C-E)$ Histogram showing ChIP-seq reads of $\mathrm{H} 3 \mathrm{~K} 4 \mathrm{me} 3(C), \mathrm{H} 3 \mathrm{~K} 4 \mathrm{mel}(D)$, and $\mathrm{H} 3 \mathrm{~K} 27 \mathrm{ac}(E) \pm 2 \mathrm{~kb}$ surrounding the peak center of sites at promoters, AEs, or PEs during interphase, prometaphase, and anaphase/telophase in U2OS (left panel) and RPE1 (right panel). In $E$, black arrow indicates reduced ChIP-seq reads of $\mathrm{H} 3 \mathrm{~K} 27 \mathrm{ac}$ from interphase to prometaphase at promoters and AEs. Red arrow indicates gained ChIP-seq reads of $\mathrm{H} 3 \mathrm{~K} 27 \mathrm{ac}$ from prometaphase to anaphase/telophase at promoters and AEs.

modifications, H3K4me3, H3K4me1, and $\mathrm{H} 3 \mathrm{~K} 27 \mathrm{ac}$, which are associated with the activation of transcription in promoters (H3K4me3, H3K27ac) or active enhancers (H3K4me1, H3K27ac). We performed immunofluores- cence in asynchronous cells and Western blotting in histone extracts from interphase, prometaphase, and anaphase/telophase enriched cells. We observed that all three histone modifications (H3K4me3, H3K4me1, and 
$\mathrm{H} 3 \mathrm{~K} 27 \mathrm{ac}$ ) were detected in all phases of mitosis from both U2OS and RPE1 cells (Supplemental Fig. S1B,C). To comprehensively examine the extent and genomic localization of mitotic occupancy of histone modifications, we performed ChIP-seq for H3K4me3, H3K4me1, and $\mathrm{H} 3 \mathrm{~K} 27 \mathrm{ac}$ in U2OS and RPE1 cell lines during interphase, prometaphase, and anaphase/telophase (Supplemental Table S1). When there is a global signal change under different experimental conditions (e.g., interphase vs. mitosis), typical normalization by the total number of mapped reads can be misleading since similar distributions of positions are sampled during sequencing. It is thus often challenging to quantitatively compare histone modification ChIP-seq data sets from different phases of the cell cycle. To overcome this, we used a spike-in based normalization strategy, whereby adding an equal amount of exogenous chromatin from a different species into each sample can be used as a more accurate normalization control (Orlando et al. 2014). We thus added spike-in chromatin from Drosophila melanogaster in each sample for global normalization and direct comparison of binding between interphase and mitotic sample (Egan et al. 2016). In accordance with previous observations (Liang et al. 2015; Javasky et al. 2018), our ChIP-seq analysis showed a significant overlap with binding sites of histone methylations between interphase and mitosis. We identified 26,276 H3K4me3 binding sites in interphase and 95\% of those sites $(25,038)$ were retained on chromatin during mitosis in U2OS and $92 \%$ of sites in RPE1. Similarly, $93 \%$ of interphase $\mathrm{H} 3 \mathrm{~K} 4 \mathrm{mel}$ binding sites in U2OS and $98 \%$ of $\mathrm{H} 3 \mathrm{~K} 4 \mathrm{me} 1$ sites in RPE1 were detected in mitosis. In contrast, consistent with previous observations (Zhiteneva et al. 2017; Ginno et al. 2018; Javasky et al. 2018), $\mathrm{H} 3 \mathrm{~K} 27 \mathrm{ac}$ showed a reduction in mitosis in both U2OS and RPE1. Only $18 \%$ of H3K27ac interphase binding sites in U2OS and $48 \%$ in RPE1 remained in mitosis (Fig. 1B). Therefore, our spike-in normalized ChIP-seq enables us to quantitatively compare the genomic localization of histone modifications during mitosis-G1.

We next asked whether the genomic distribution of histone modifications between interphase and mitosis appears to be uniform or different at active regulatory elements. We first classified promoter $\left(\mathrm{H} 3 \mathrm{~K} 4 \mathrm{me} 3^{+}\right.$, proximity to TSS), PE (H3K4me1 $1^{+}$, distal to TSS), and AE $\left(\mathrm{H} 3 \mathrm{~K} 27 \mathrm{ac}^{+} / \mathrm{H} 3 \mathrm{~K} 4 \mathrm{mel}^{+}\right.$, distal to TSS) elements based on our ChIP-seq data (Supplemental Fig. S1D; Creyghton et al. 2010; Calo and Wysocka 2013). We then compared histone modification levels across the cell cycle at these elements. As has been shown before, interphase H3K4me3 peaks were preferentially bound at TSS (Supplemental Fig. S1E, left panel) and H3K4me1 peaks were depleted at TSS (Supplemental Fig. S1E, right panel; Heintzman et al. 2009; Creyghton et al. 2010). During mitosis, H3K4me3 binding was significantly enriched, comparable with interphase at promoters (Fig. 1C). Mitotic H3K4me1 was also detected at a similar level in interphase, but with slightly higher levels at AEs and PEs (Fig. 1D). In contrast, we observed signal reduction in $\mathrm{H} 3 \mathrm{~K} 27 \mathrm{ac}$ levels in the prometaphase cells at both promoters and AEs and its signals recovered in anaphase/telophase. The reduction of
$\mathrm{H} 3 \mathrm{~K} 27 \mathrm{ac}$ binding was observed in both promoters and AEs with similar levels, however the recovery of binding in anaphase/telophase was more pronounced at promoters (Fig. 1E), suggestive of the promoter-specific function of H3K27ac during anaphase/telophase. Altogether, these results demonstrate that, based on the number of binding sites and binding distribution at cis-REs of histone modifications, $\mathrm{H} 3 \mathrm{~K} 4 \mathrm{me} 3$ and $\mathrm{H} 3 \mathrm{~K} 4 \mathrm{mel}$ are globally retained during mitosis, while $\mathrm{H} 3 \mathrm{~K} 27 \mathrm{ac}$ is lost in prometaphase and regained as cells exit mitosis.

\section{Promoters maintain H3K4me3 and enhancers maintain H3K4me1 in the absence of H3K27ac during prometaphase}

We next wanted to determine how gene regulatory elements "remember" their histone modification dynamics across mitosis. To answer this question, we selected all promoters and enhancers from interphase and compared the dynamics of each histone modification from interphase to prometaphase or to anaphase/telophase cells. Promoters can be marked by either H3K4me3 only or by both H3K27ac and H3K4me3. We found that the majority of $\mathrm{H} 3 \mathrm{~K} 4 \mathrm{me} 3+$ promoters remained in prometaphase $(98.3 \%)$. In contrast, only $1.1 \%$ of promoters remained associated with $\mathrm{H} 3 \mathrm{~K} 27 \mathrm{ac}$ in prometaphase and $87 \%$ of $\mathrm{H} 3 \mathrm{~K} 4 \mathrm{me} 3+$ promoters were able to regain $\mathrm{H} 3 \mathrm{~K} 27 \mathrm{ac}$ in anaphase/telophase (Fig. 2A,B; Supplemental Fig. S2A,B). Only a small fraction of interphase AEs retained H3K27ac in prometaphase $(18.0 \%)$. Of AEs, $69.2 \%$ lost $\mathrm{H} 3 \mathrm{~K} 27 \mathrm{ac}$, but retained $\mathrm{H} 3 \mathrm{~K} 4 \mathrm{mel}$ in prometaphase cells (Fig. 2C,D; Supplemental Fig. S2C,D). We found that the majority of PEs remained stable in prometaphase and anaphase/telophase $(89.4 \%$ and $86.6 \%$, respectively) similar to $\mathrm{H} 3 \mathrm{~K} 4 \mathrm{me} 3^{+}$promoters (Fig. 2E,F; Supplemental Fig. $\mathrm{S} 2 \mathrm{E}, \mathrm{F})$. These data suggest that promoters and enhancers continue to retain $\mathrm{H} 3 \mathrm{~K} 4 \mathrm{me} 3$ and $\mathrm{H} 3 \mathrm{~K} 4 \mathrm{me} 1$ respectively, as potential bookmarks, although they lose H3K27ac during prometaphase.

\section{H3K4me1 remains at enhancers of cell type-specific genes during prometaphase}

Next, we asked whether continuous retention of H3K4mel during prometaphase associates with a bookmark of cell type-specific genes. For this, we used U2OS cells, which are derived from cells of mesenchymal origin that differentiate to osteoblasts. There are several genes identified as essential for bone formation and differentiation to osteoblasts. These so-called osteoblast-specific genes include RUNX2, TNFRSF11B, DKK1, SP7, ALPL, $M S X 2, C O L 1 A 2$, and SOST (Kirkham and Cartmell 2007; Chapurlat and Confavreux 2016; Rutkovskiy et al. 2016). Strikingly, all of these genes were associated with mitotic H3K4me1 at enhancers (RUNX2, TNFRSF11B, and $A L P L$ shown in Fig. 3A). Consistent with U2OS cells, RPE1 cells also showed that H3K4mel during prometaphase was associated with RPE-specific genes (Zhang et al. 2012) such as ALDH1A3, EFEMP1, GJA1, TIMP3, AHR, TYRP1, LAMP2, SLC16A4, BMP4, VEGFA, and 
A

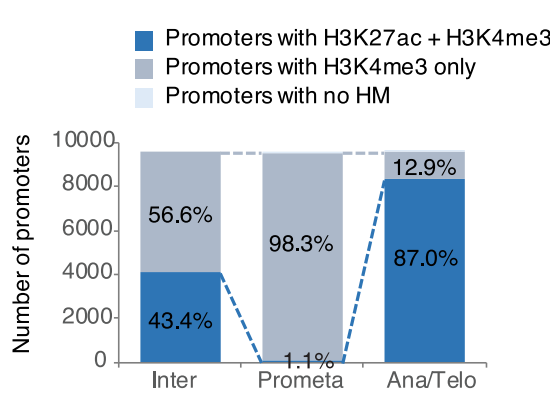

C

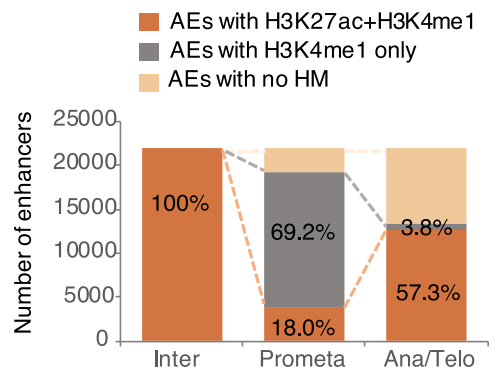

$\mathbf{E}$

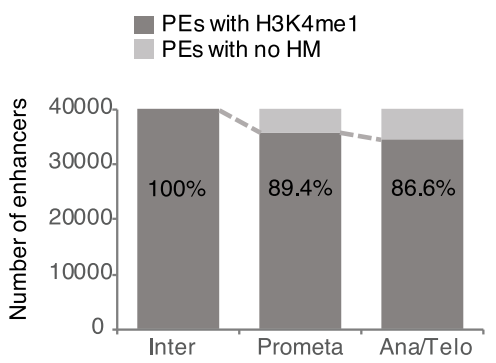

B

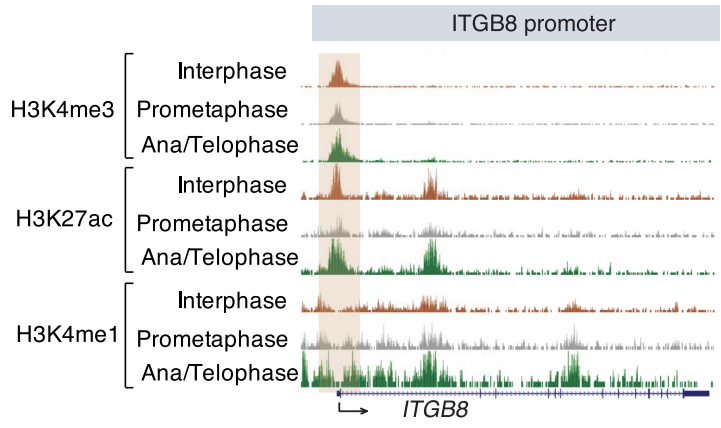

D

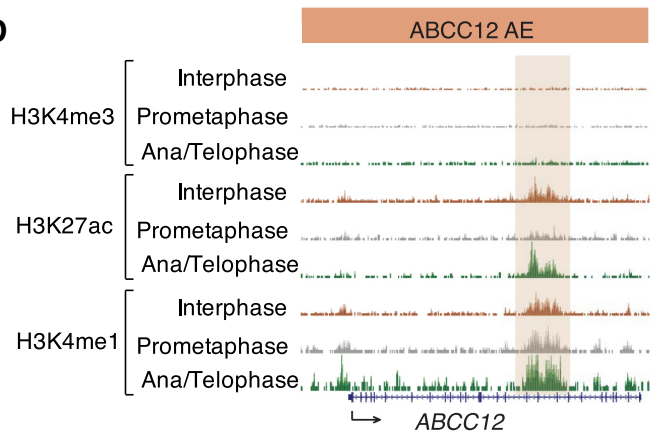

$\mathbf{F}$

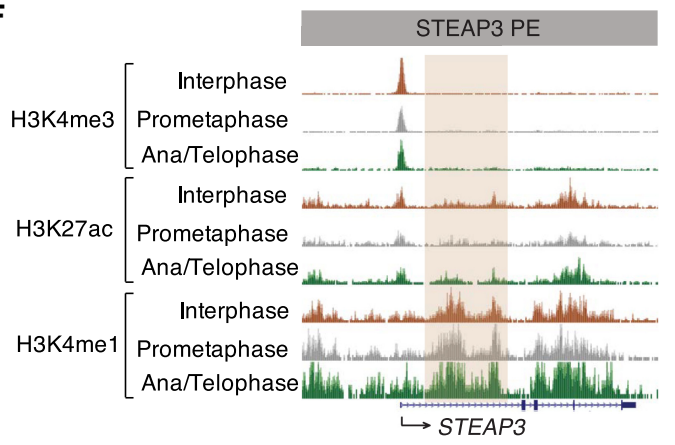

Figure 2. Histone methylations bookmark promoters and enhancers in the absence of H3K27ac during prometaphase. (A) Quantification of interphase promoters that are also detected in prometaphase or in anaphase/telophase. Promoters harboring both H3K27ac and $\mathrm{H} 3 \mathrm{~K} 4 \mathrm{me} 3$ are shown in blue and H3K4me3 only in light blue. Promoters not containing any histone modification are shown in the lightest blue color. $(B)$ ChIP-seq tracks at the promoter of the ITGB8 gene for H3K4me3, H3K27ac, and H3K4me1 during interphase, prometaphase, and anaphase/telophase. $(C)$ Quantification of interphase AEs that are also detected in prometaphase or in anaphase/telophase. AEs harboring both $\mathrm{H} 3 \mathrm{~K} 27 \mathrm{ac}$ and $\mathrm{H} 3 \mathrm{~K} 4 \mathrm{me} 1$ are shown in orange and $\mathrm{H} 3 \mathrm{~K} 4 \mathrm{mel}$ only in gray. AEs not containing any histone modification are shown in light orange. (D) ChIP-seq tracks at AE of ABCC12 gene for H3K4me3, H3K27ac, and H3K4mel during interphase, prometaphase, and anaphase/telophase. (E) Quantification of interphase PEs that are also detected in prometaphase or in anaphase/telophase. PEs harboring H3K4me1 are shown in gray. PEs not containing any histone modification are shown in light gray. $(F)$ ChIP-seq tracks at PE of STEAP3 gene for H3K4me3, H3K27ac, and H3K4me1 during interphase, prometaphase, and anaphase/telophase. Peaks are highlighted by brown boxes. (Inter) Interphase; (Prometa) prometaphase; (Ana/telo anaphase/telophase); (HM) histone modification.

PRNP (ALDH1A3, EFEMP1, and GJA1 shown in Fig. 3B). Next, we wanted to investigate whether mitotic histone modification binding sites are linked to genes with distinct biological functions. To do so, we performed Genomic Regions Enrichment of Annotations Tool (GREAT) (McLean et al. 2010) analysis on the promoters and enhancers in U2OS and RPE1 cells (Supplemental Fig. S3; Supplemental Table S2). Notably, promoters retaining H3K4me3 during prometaphase, were strongly enriched for genes involved in fundamental cellular processes, such as RNA and protein metabolism, whereas AEs either retaining or losing $\mathrm{H} 3 \mathrm{~K} 27 \mathrm{ac}$ during prometaphase were predominantly linked to differentiation or developmentrelated genes in both cell lines. Specifically, we observed that AEs losing $\mathrm{H} 3 \mathrm{~K} 27 \mathrm{ac}$, but retaining $\mathrm{H} 3 \mathrm{~K} 4 \mathrm{mel}$ were most strongly associated with genes involved in bone mineralization in U2OS (Supplemental Fig. S3A, bottom panel). Together, these results indicate that enhancers use $\mathrm{H} 3 \mathrm{~K} 4 \mathrm{me} 1$ to maintain their cellular identity upon loss of H3K27ac throughout mitosis.

Previous studies demonstrated that although most TFs and cofactors are removed from mitotic chromatin, 
Kang et al.

A

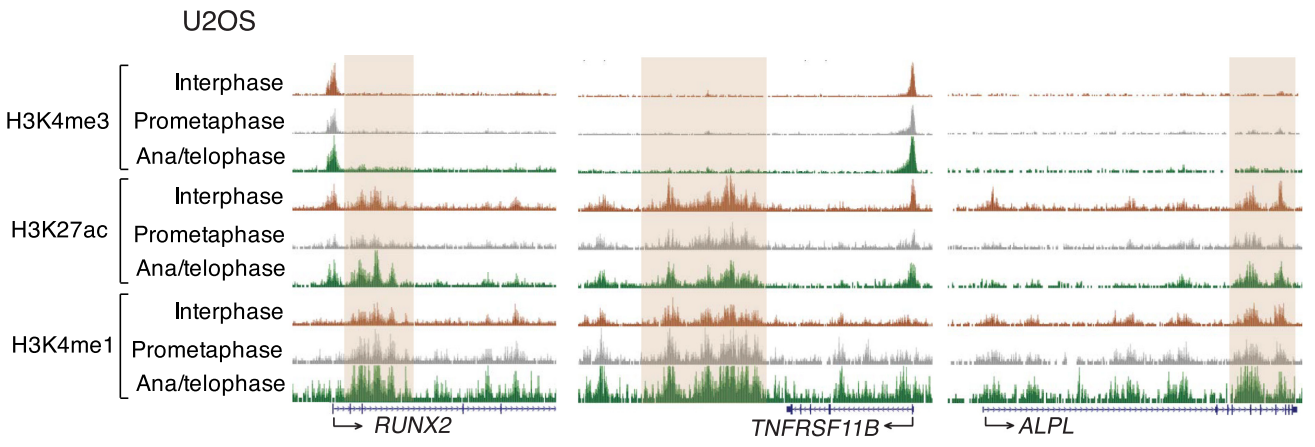

B RPE1

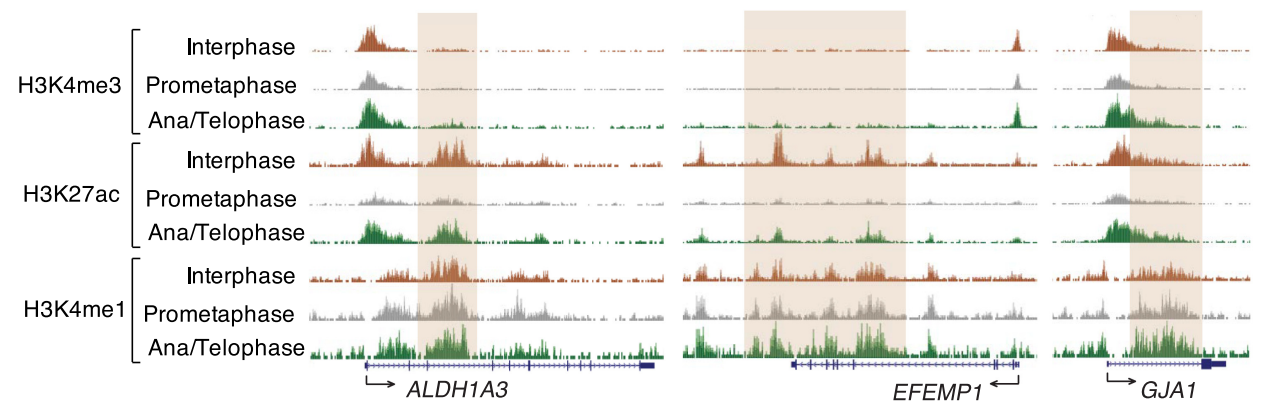

C

\begin{tabular}{|c|c|c|c|c|}
\hline \multirow{3}{*}{$\begin{array}{l}\text { Transcription } \\
\text { Factor }\end{array}$} & \multirow{3}{*}{ Motif } & \multicolumn{3}{|c|}{ P-value } \\
\hline & & Book & arked & ments \\
\hline & & $\mathrm{Pr}$ & $\mathrm{AE}$ & PE \\
\hline FOSL2 & 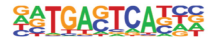 & $1 \mathrm{e}^{-0}$ & $1 e^{-75}$ & $1 e^{-819}$ \\
\hline JUN-AP1 & 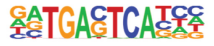 & $1 e^{-0}$ & $1 e^{-66}$ & $1 e^{-772}$ \\
\hline FRA2 & 돌수럳CTCATC & $1 e^{-0}$ & $1 e^{-99}$ & $1 e^{-817}$ \\
\hline FRA1 & 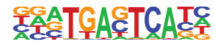 & $1 e^{-0}$ & $1 e^{-94}$ & $1 e^{-817}$ \\
\hline JUNB & КATGACTCAT & $1 e^{-0}$ & $1 e^{-84}$ & $1 e^{-779}$ \\
\hline
\end{tabular}

D

\begin{tabular}{|c|c|c|c|c|}
\hline \multirow[b]{2}{*}{$\begin{array}{l}\text { Transcription } \\
\text { Factor }\end{array}$} & \multirow[b]{2}{*}{ Motif } & \multicolumn{3}{|c|}{ P-value } \\
\hline & & $\begin{array}{l}\text { Bookl } \\
\mathrm{Pr}\end{array}$ & $\begin{array}{c}\text { arked } \\
\mathrm{AE}\end{array}$ & $\begin{array}{l}\text { ements } \\
P E\end{array}$ \\
\hline RUNX1 & C्रAAA & $1 e^{-0}$ & $1 e^{-1}$ & $1 e^{-33}$ \\
\hline RUNX-AML & ㅜㅜㄹ숙GTGGTIE & $1 \mathrm{e}^{-0}$ & $1 e^{-1}$ & $1 \mathrm{e}^{-26}$ \\
\hline RUNX2 & 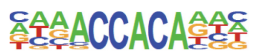 & $1 \mathrm{e}^{-0}$ & $1 e^{-1}$ & $1 e^{-24}$ \\
\hline TEAD1 & CCACATTCCA & $1 e^{-1}$ & $1 e^{-9}$ & $1 \mathrm{e}^{-122}$ \\
\hline TEAD3 & TCEXATTCCAG & $1 \mathrm{e}^{-0}$ & $1 e^{-9}$ & $1 e^{-108}$ \\
\hline TEAD & 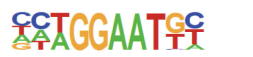 & $1 \mathrm{e}^{-0}$ & $1 e^{-7}$ & $1 e^{-107}$ \\
\hline FOXL2 & AATGTAAACA로옹 & $1 e^{-1}$ & $1 e^{-1}$ & $1 e^{-11}$ \\
\hline FOXA1 & AAAGTAAACA & $1 \mathrm{e}^{-0}$ & $1 e^{-0}$ & $1 e^{-7}$ \\
\hline FOXO3 & 台GTAAACA & $1 e^{-1}$ & $1 e^{-0}$ & $1 e^{-6}$ \\
\hline
\end{tabular}

Figure 3. H3K4me1 remains at enhancers of cell type-specific genes during prometaphase. $(A)$ Representative genome browser tracks showing cobinding of osteoblast-specific genes (RUNX2, TNFRSF11B, and $A L P L$ ) with mitotic H3K4me1 at enhancers. (B) Representative genome browser tracks showing cobinding of RPE-specific genes (ALDH1A3, EFEMP1, and GJA1) with mitotic H3K4me1 at enhancers. Peaks are highlighted by brown boxes. (C) TF motif enrichments for bookmarked promoter (Pr, blue), AE (orange), and PE (gray) during mitosis. Sequence logos and $P$ values are shown for the most highly enriched sequence motifs among the top 10 . $(D)$ Motif analysis of TFs-regulating osteoblast differentiation (RUNXs, TEADs, and FOXOs) for bookmarked promoter (Pr, blue), AE (orange), and PE (gray).

several tissue-specific or pathway-specific TFs such as RUNX2, GATA1, or FOXA1 remain bound on mitotic chromosomes to a subset of their interphase sites (Young et al. 2007; Kadauke et al. 2012; Caravaca et al. 2013). To determine the factors that associate with mitotic histone modifications at cis-REs, we performed de novo motif analysis of the bookmarked elements in U2OS cells. Our analysis showed that both AEs and PEs were preferentially enriched with motifs of the activator protein-1 (AP1) family of TFs including FOSL2, JUN-AP1, FRA2, FRA1, and JUNB (Fig. 3C), which has an essential role in osteo- blast differentiation and collagen production by regulating osteoblast-lineage gene expression in bone cells (Jochum et al. 2000; Sabatakos et al. 2000; Kveiborg et al. 2004; Bozec et al. 2010). In addition to AP-1 TFs, we next sought to determine whether genomic regions harboring mitotic histone marks were enriched for TFs binding that has been known to regulate osteoblast differentiation such as RUNXs (Komori 2005), TEADs (Kegelman et al. 2018), and FOXOs (Rached et al. 2010; Teixeira et al. 2010). Our analysis revealed that these TFs regulating osteoblast-specific gene expression had preferential binding 
at PEs compared with AEs and promoters (Fig. 3D). A prior study shows that RUNX2, an essential TF for osteogenic cell fates, remains associated with mitotic chromosomes in multiple cell lines, including Saos-2 osteosarcomas and HeLa cells (Young et al. 2007). Therefore, combined with previous observations, we conclude that retention of mitotic $\mathrm{H} 3 \mathrm{~K} 4 \mathrm{mel}$ peaks at enhancer regions provides a platform for interaction with a subset of cell type-specific TFs during and after mitosis.

\section{Regained H3K27ac in anaphase/telophase is positively correlated with gene reactivation}

Histone modifications are found on mitotic chromatin with either a stable $(\mathrm{H} 3 \mathrm{~K} 4 \mathrm{me} 1 / 3)$ or reduced (H3K27ac) abundance when compared with interphase chromatin (Fig. 1). Together with an association with mitotic chromatin, it has been suggested that one feature of mitotic bookmarking is to enable activation of a defined transcriptional program after mitosis (Kouskouti and Talianidis 2005; Valls et al. 2005; Muramoto et al. 2010; Zhao et al. 2011). To determine whether occupancy of mitotic histone modifications associates with postmitotic transcriptional activation, we first examined temporal dynamics of gene expression during the mitosis-G1 transition. To do that, we labeled nascent transcripts with uridine ana$\log$, 5'-ethynyl uridine (EU) for $35 \mathrm{~min}$, prior to isolation of RNA, during prometaphase, anaphase/telophase, cytokinesis, and various G1 phases (Supplemental Fig. S4A). Then, we captured nascent RNA by adding biotin-azide and generated cDNA libraries for sequencing. As there was a large difference in the amount of nascent RNA between interphase and mitotic cells, we used external controls that appropriately normalize the RNA-seq data (Supplemental Fig. S4B; Supplemental Table S1; Palozola et al. 2017). Based on normalized FPKM, genes were divided into seven classes, first activated at $0 \mathrm{~min}, 35 \mathrm{~min}, 60 \mathrm{~min}$, $90 \mathrm{~min}, 120 \mathrm{~min}, 180 \mathrm{~min}$, and asynchronous (Supplemental Table S3). Consistent with the previous study, we found a hierarchy of gene reactivation at the mitosis to G1 transition (Fig. 4A; Palozola et al. 2017). We also found a subset of genes expressed in mitosis (431 genes at 0 min and 2284 genes at $35 \mathrm{~min}$ ) and the largest number of genes first activated at $60 \mathrm{~min}$ when most of the cells are at cytokinesis (Fig. 4B). Gene Ontology (GO) enrichment analysis showed that genes first activated at $60 \mathrm{~min}$ are involved in basic cellular functions such as cellular organization, cell cycle progression, and RNA and protein metabolism. Conversely, genes expressed at later time points are linked to bone development (Fig. 4C). However, these cell type-specific genes may be expressed at all times, but just overrepresented at the later time points, given that genes related to basic functions are first activated at the earlier time point by 60 min, when the majority of genes $(88 \%)$ are expressed.

Next, we asked whether the presence of investigated histone modifications correlates with transcriptional activation during and after mitosis. To do that, we tested the Pearson correlation coefficient between transcription level of genes first activated at each time point and the read counts for histone modifications, at promoters versus
AEs, and in each cell cycle phase. We found that at promoters, gene expression at $60 \mathrm{~min}$ was positively correlated with H3K4me3 or H3K27ac levels throughout all cell cycle phases. Notably, among the positive correlations, we found that genes whose promoters were associated with anaphase/telophase H3K27ac were most strongly correlated $(R=0.60)$ (Fig. 4D). Furthermore, we observed that all genes first activated at each time point showed the most positive correlation with anaphase/telophase H3K27ac at promoters (Supplemental Fig. 4C). AEs are associated with active transcription by bringing DNA loops physically close to gene promoters. However, for AEs, either $\mathrm{H} 3 \mathrm{~K} 27 \mathrm{ac}$ or H3K4me1 level in mitosis was not positively correlated with gene expression (Fig. 4D). Altogether, these results indicate that recovery of $\mathrm{H} 3 \mathrm{~K} 27 \mathrm{ac}$ at promoter regions in anaphase/telophase may be important for the reactivation of transcriptional programs in the daughter cells.

We observed that $\mathrm{H} 3 \mathrm{~K} 4 \mathrm{me} 1$ at enhancers remains associated with cell type-specific genes during prometaphase (Fig. 3C; Supplemental Fig. S3). We thus asked whether H3K4me1 occupancy throughout mitosis associates with rapid transcriptional activation of cell type-specific genes. We obtained the list of 113 genes specifically expressed in bone or bone marrow, which are also expressed in U2OS, using the Tissue-specific Gene Expression and Regulation (TiGER) database (Liu et al. 2008). This number was similar to the 149 liver-specific genes in HUH7 human hepatoma cells seen in a prior study (Palozola et al. 2017). We then analyzed the time when the 113 bone-specific genes are first activated across mitosis and found that bone-specific genes follow general gene expression pattern: Most are reactivated at $60 \mathrm{~min}$. Interestingly, however, there was a higher percentage of bone-specific genes first activated at 0 min, compared with EU-labeled total genes (Fig. 4E). To investigate whether bone-specific genes expressed at 0 min tend to contain mitotic histone marks at enhancers, the number of bone genes was counted at each time point based on its occupancy with either promoters retaining $\mathrm{H} 3 \mathrm{~K} 4 \mathrm{me} 3$ or enhancers retaining $\mathrm{H} 3 \mathrm{~K} 27 \mathrm{ac} / \mathrm{H} 3 \mathrm{~K} 4 \mathrm{me} 1$ during prometaphase. Strikingly, mitotic AEs and PEs showed higher enrichment for 0 min expressing bone-specific genes than EU-labeled total genes (Fig. 4G,H), while mitotic promoters did not show any particular enrichment for 0 min expressing bone-specific genes (Fig. 4F). This suggests that activation of early expressing bone-specific genes may involve association with mitotic $\mathrm{H} 3 \mathrm{~K} 4 \mathrm{me}$ 1 together with $\mathrm{H} 3 \mathrm{~K} 27 \mathrm{ac}$ at enhancers.

\section{H3K27ac functions as a transcriptional bookmark}

Mitotic occupancy of histone modifications is associated with postmitotic gene activation suggestive of mitotic bookmarking. However, a recent study showed that inhibition of mitotic BRD4 binding did not affect transcriptional activation, suggesting that mitotic occupancy can be passively bound to mitotic chromatin and dispensable for transcription (Behera et al. 2019). To test whether $\mathrm{H} 3 \mathrm{~K} 27 \mathrm{ac}$ has a functional bookmarking role in postmitotic activation of transcription, we examined how 
Kang et al.

A

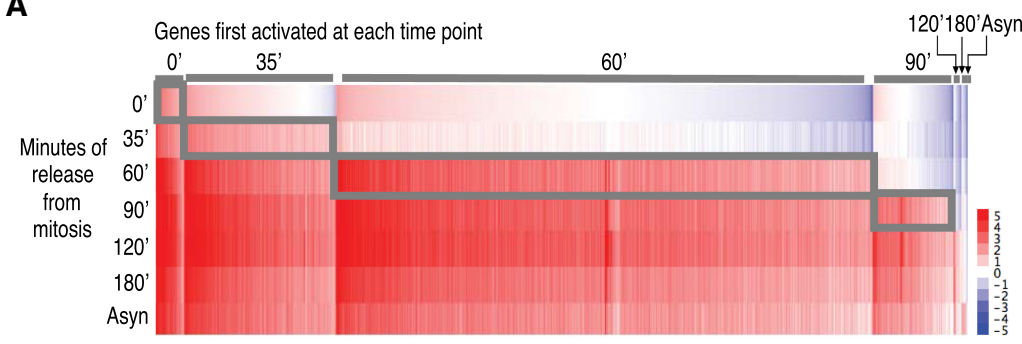

C

\begin{tabular}{|c|c|c|c|c|}
\hline 0' prometaphase & $35^{\prime}$ anaphase/telophase $\rightarrow$ & 60 ' cytokinesis/early G1 & 90' G1 & 120' G1 \\
\hline $\begin{array}{l}\text { Cellular component organization } \\
\text { Cell division } \\
\text { Protein repair } \\
\text { ITGB2, CCNB1, PCMT1 }\end{array}$ & $\begin{array}{l}\text { Organelle organization } \\
\text { Cell division } \\
: \text { G2/M transition } \\
: \text { sister chromatid segregation } \\
\text { : APC mediated degradation } \\
\text { Cellcell adhesion } \\
\text { NUPS, SMC3, FBXW11, CDKS }\end{array}$ & $\begin{array}{l}\text { Cellular metabolic process } \\
\text { Nucleic acid metabolic process } \\
\text { RNA metabolic processes } \\
\text { SPTBN2, DCP1B, RPLs } \\
\end{array}$ & $\begin{array}{l}\text { Organ morphogenesis } \\
\text { Skeletal development } \\
\text { Cartilage development } \\
\text { HOXCs, WNTS, SMADs, } \\
\text { FGF2, CTSK }\end{array}$ & $\begin{array}{l}\text { B cell differentiation } \\
\text { Chondrocyte development } \\
\text { GPR183, CHST11, FGF18 }\end{array}$ \\
\hline
\end{tabular}

D

Promoter

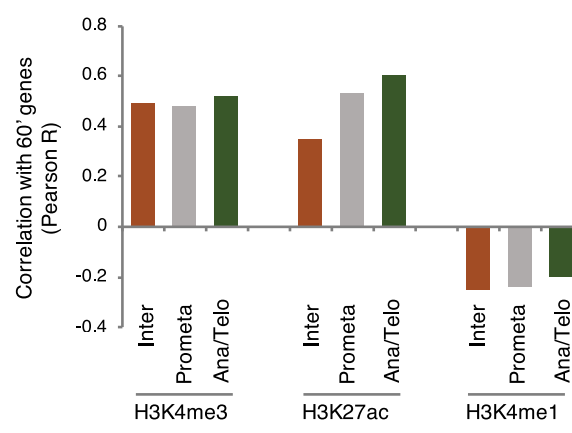

E

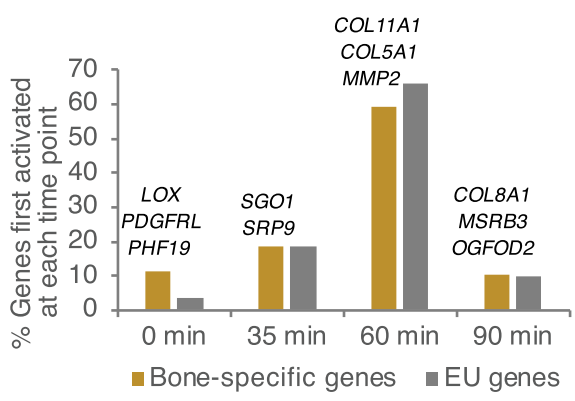

G

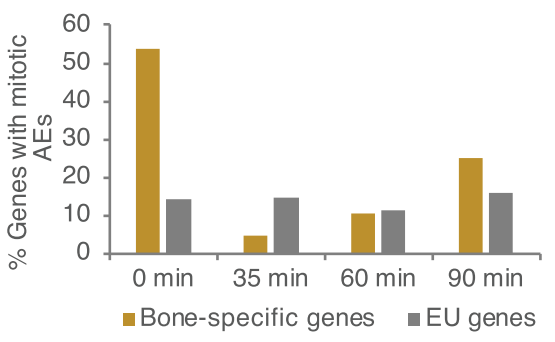

B

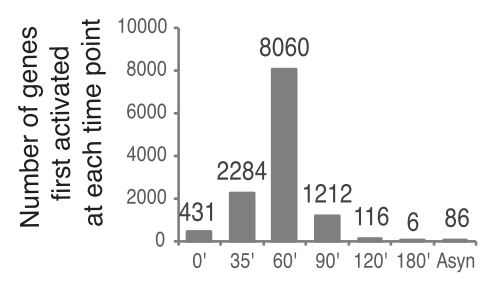

AE

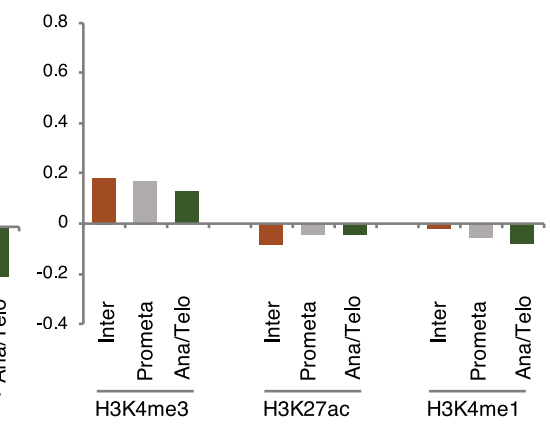

F

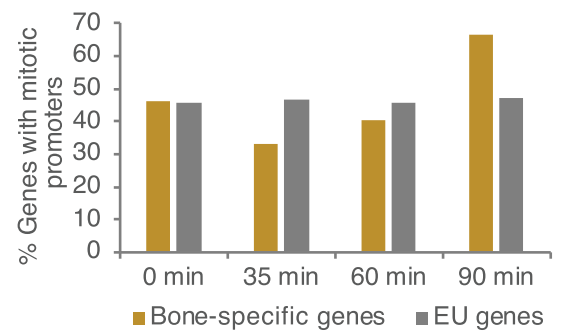

H

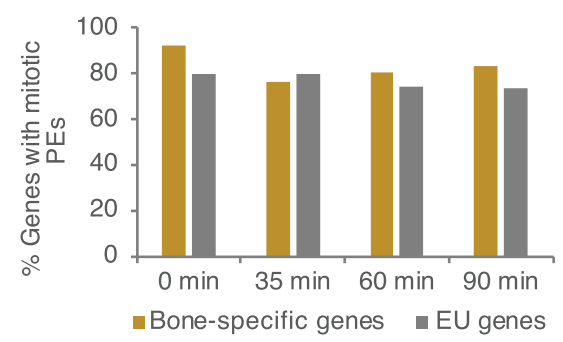

Figure 4. Activation of transcriptional programs during mitosis-G1 is associated with histone modification binding. (A) EU-RNA-seq data heat map illustrating the relative expression of genes first activated at each time point during mitosis-G1. (B) Number of EU labeled genes first activated at each time point. $(C)$ Representative GO terms at each time point. $(D)$ Pearson correlation coefficient $(\mathrm{R})$ was determined between 60-min transcriptional level and the ChIP-seq reads of H3K4me3, H3K27ac, and H3K4me1 in interphase (Inter), prometaphase (Prometa), and anaphase/telophase (Ana/Telo) at promoter and AE, defined in Supplemental Figure S1D. (E-H) Bar plot showing the percentage of genes first activated at each time point. $(E)$ Representative bone-specific genes are indicated at each time point. Percentage of genes containing mitotic promoters $(F)$, mitotic AEs $(G)$, and mitotic PEs $(H)$ at each time point. Bone-specific genes are shown in yellow and EU genes are in gray. 
inhibition of H3K27ac affects gene expression. We used the p300/CBP catalytic inhibitor A-485 (Lasko et al. 2017) to inhibit (1) mitotic H3K27ac occupancy or (2) recovery of H3K27ac from anaphase/telophase. First, we observed by Western blot that 1 -h treatment of A-485 effectively reduced $\mathrm{H} 3 \mathrm{~K} 27 \mathrm{ac}$ binding from nocodazole-arrested prometaphase cells (Supplemental Fig. S5A, left panel). We then washed out both nocodazole and A-485 and released cells for $1 \mathrm{~h}$ or $24 \mathrm{~h}$. Reduced H3K27ac binding from prometaphase chromatin was able to regain as cells exit mitosis to enter 1 -h cytokinesis or $24-\mathrm{h}$ next cell cycle (Supplemental Fig. S5A, middle panel). Second, to inhibit $\mathrm{H} 3 \mathrm{~K} 27 \mathrm{ac}$ regaining from anaphase/telophase, we released cells from mitotic arrest while treating with A-485 for 1 or $3 \mathrm{~h}$. The H3K27ac levels successfully decreased in both 1-h and 3-h treatment with A-485 (Supplemental Fig. S5A, right panel). Next, nascent transcripts were pulse-labeled with the EU followed by sequencing and normalized by spike-in controls (Fig. 5A; Supplemental Table S1). We confirmed by EU-RNA-seq analysis that the biological replicates for each treatment were highly correlated (Supplemental Fig. S5B) and that A-485 treatment resulted in extensive transcriptional changes for all treatments (Supplemental Fig. S5C).

We first explored whether A-485 treatment alters postmitotic transcriptional activation. Genes were clustered into three groups based on $\log _{2}$ fold change (down-regulated, up-regulated, and no change) upon A-485 treatment. When inhibiting mitotic H3K27ac, 56\% (48\% down and $8 \%$ up) of the genes in prometaphase and $45 \%(29 \%$ down and $16 \%$ up) of the genes in cytokinesis were dysregulated. Since the length of the cell cycle is $\sim 24 \mathrm{~h}$ for dividing mammalian cells, we let cells enter the next cell cycle upon mitotic inhibition of H3K27ac. Surprisingly, 45\% (22\% down and $23 \%$ up) of the genes in 24-h release cells were dysregulated, suggesting that mitotic $\mathrm{H} 3 \mathrm{~K} 27 \mathrm{ac}$ is required for maintaining transcriptional memory. H3K27ac begins to get regained from anaphase/telophase (Fig. 1) and is the most predictive histone mark for gene reactivation (Fig. 4D), suggestive of a transcriptional bookmark. We thus investigated the functional role of $\mathrm{H} 3 \mathrm{~K} 27 \mathrm{ac}$ recovery from anaphase/telophase in mitotic bookmarking. When inhibiting recovery of $\mathrm{H} 3 \mathrm{~K} 27 \mathrm{ac}, 45 \%$ (23\% down and $22 \%$ up) of the genes in cytokinesis were dysregulated and $50 \%$ (23\% down and $27 \%$ up) of the genes in $3 \mathrm{~h} \mathrm{G1}$ were also dysregulated (Fig. 5B). This suggests that postmitotic transcriptional activation requires the recovery of H3K27ac. GO enrichment analysis showed that genes down-regulated in all A-485-treated cells after cytokinesis were significantly enriched in gene sets involved in mRNA/protein metabolism and cell-cell adhesion (Fig. $5 \mathrm{C})$, supporting the idea that faithful transmission of transcriptional programs requires both mitotic $\mathrm{H} 3 \mathrm{~K} 27 \mathrm{ac}$ occupancy and H3K27ac recovery from anaphase/telophase.

Since transcription rate gradually increases as cells exit mitosis to enter the G1 phase (Fig. 4A), we hypothesized that perturbation of transcriptional activation by A- 485 treatment would get recovered as cells get into late G1 (3-h G1) from early G1 (cytokinesis). However, we noticed that the extent of down-regulated and up-regulated genes was consistent between cells in cytokinesis and 3-h G1 upon A-485 treatment (Fig. 5D, right panel). The extent of down-regulated or up-regulated genes was also consistent between cells in cytokinesis and 24-h release upon inhibition of mitotic H3K27ac (Fig. 5D, left panel). Therefore, the dysregulated genes by both inhibiting mitotic $\mathrm{H} 3 \mathrm{~K} 27 \mathrm{ac}$ and $\mathrm{H} 3 \mathrm{~K} 27 \mathrm{ac}$ recovery were not able to recover their own transcriptional activity in the daughter cells. These data suggest that H3K27ac during prometaphase and anaphase/telophase is essential for the activation of postmitotic transcription, rather than regulates transcriptional rate.

Given that bone-specific genes expressed early tend to contain mitotic H3K27ac (Fig.4G), we hypothesized that removal of $\mathrm{H} 3 \mathrm{~K} 27 \mathrm{ac}$ from mitotic chromatin would affect the early activation of bone-specific genes. Indeed, A-485 treatment during mitosis altered expression in bone-specific genes. Bone-specific genes at the 0 min timepoint were most noticeably down-regulated upon mitotic inhibition of H3K27ac (Fig. 5E). This indicates that mitotic $\mathrm{H} 3 \mathrm{~K} 27 \mathrm{ac}$ is required for rapid transcriptional activation of cell type-specific genes.

\section{Long-range chromatin interactions are established} between 90 and $120 \mathrm{~min}$ after release from mitotic arrest

Long-range chromatin interactions are lost in prometaphase and reformed in early G1 (Naumova et al. 2013; Abramo et al. 2019). However, the role of TADs interactions during anaphase/telophase and whether they are already reestablished during anaphase/telophase to enable gene reactivation at cytokinesis remain unclear. To investigate when long-range interactions are reformed, we performed $\mathrm{Hi}-\mathrm{C}$ to detect physical interactions between distant genomic elements, from prometaphase to 360-min G1 (Supplemental Table S1). We assessed the reproducibility of Hi-C data between two biological replicates and observed a strong Pearson correlation coefficient at all time points (Supplemental Fig. S6). In agreement with previous observations, Hi-C contact maps showed that chromosomal interactions were no longer observed in mitotic cells (Naumova et al. 2013; Nagano et al. 2017; Gibcus et al. 2018; Oomen et al. 2019) including 0-min (prometaphase) and 35-min (anaphase/telophase) chromatin and appeared after $60 \mathrm{~min}$ (cytokinesis) (Fig. 6A; Abramo et al. 2019). We observed that A-A and B-B compartments, TADs, and DNA loops between promoters and enhancers were no longer detected in prometaphase and started to reveal interactions from $60 \mathrm{~min}$ and completed between 90 and $120 \mathrm{~min}$ (Fig. 6B-D). Because long-range interactions are reformed after $60 \mathrm{~min}$ when the transcriptional program is reestablished, we reasoned that the formation of long-range interactions does not appear to be necessary for the majority of gene reactivation.

\section{CTCF and active histone modifications bookmark} the TAD boundaries across mitosis

It has been shown previously that the TAD boundaries are enriched in CTCF binding (Dixon et al. 2012; Rao et al. 
Kang et al.

A

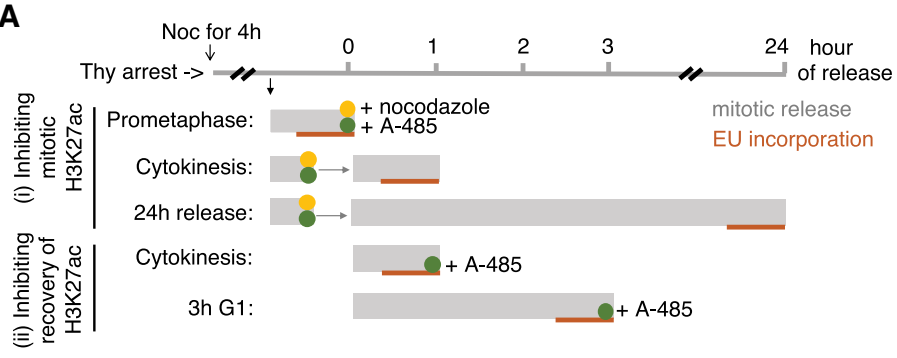

C

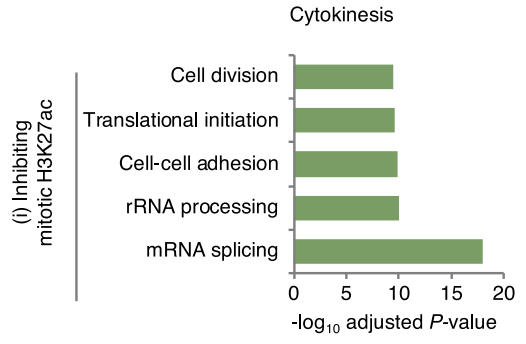

Cytokinesis

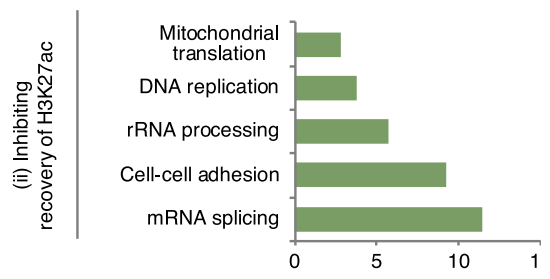

D

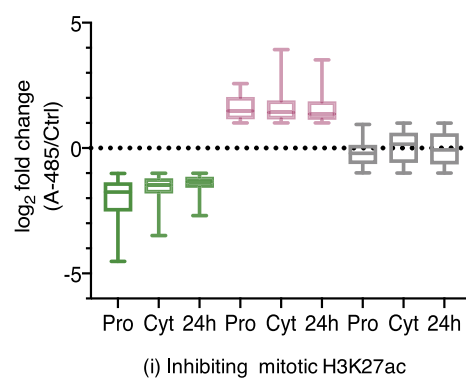

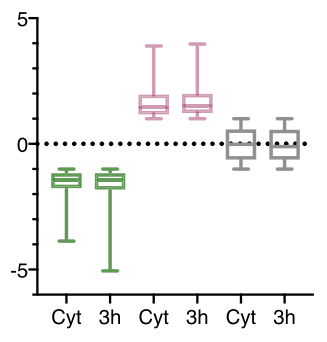

(ii) Inhibiting recovery of $\mathrm{H} 3 \mathrm{~K} 27 \mathrm{ac}$

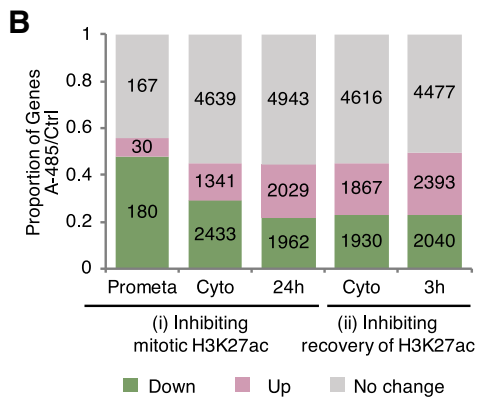

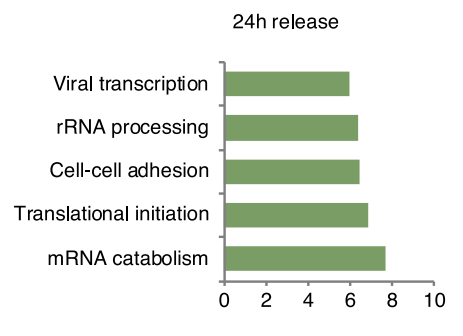

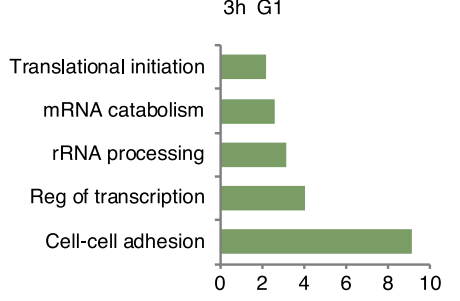

$\mathrm{E}$

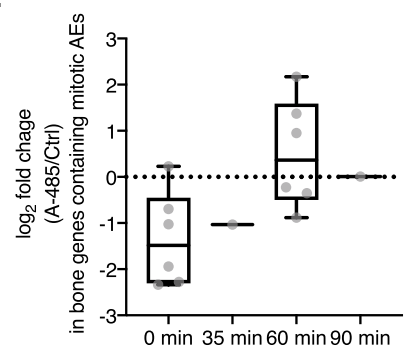

Figure 5. H3K27ac serves as a mitotic bookmark. (A) Schematic of EU-RNA-seq strategy illustrating strategies to test bookmarking function. A-485 was used to inhibit H3K27ac binding during and after mitosis. (B) Proportion of genes down-regulated or up-regulated, or with no change due to A-485 treatment in each cell cycle phase. The number of each group of genes is indicated. Down-regulated genes (green, $\log _{2}$ fold change $<-1$ ); Up-regulated genes (red, $\log _{2}$ fold change $\left.>1\right)$. (C) Top five GO enriched for down-regulated genes in A-485 treated cells. Bar length represents the $-\log _{10}$ adjusted $P$-value. $(D)$ Box and whisker plots of the $\log _{2}$ fold change in each cell cycle phase on treatment with A-485 across down-regulated, up-regulated, and no change genes. Midline equals the median, top of box equals 75 th percentile, and bottom of box equals 25th percentile. Upper and lower whiskers equal the maximum and the minimum, respectively. $(E)$ Box plot displaying the $\log _{2}$ fold change in expression of bone genes containing mitotic AEs at each time point upon A-485 treatment. Each gene is indicated with a dot (gray).

2014; Vietri Rudan et al. 2015) and imaging analysis detects CTCF on mitotic chromatin, yet with reduced levels (Burke et al. 2005). To investigate how properly TADs are formed after mitosis, we asked whether a subset of CTCF is retained at the TAD boundaries across mitosis and acts as a bookmark for TAD formation. To do that, we first performed ChIP-seq for CTCF in prometaphase, anaphase/ telophase, and interphase and analyzed retention of CTCF binding and its genome-wide distribution during mitosis. In accordance with a recent study, CTCF is largely depleted from mitotic chromatin (Oomen et al. 2019). We identified $<3 \%$ of the total binding peaks in prometaphase (Supplemental Fig. S7C). In concordance with our ChIP-seq analysis, immunofluorescence and Western 

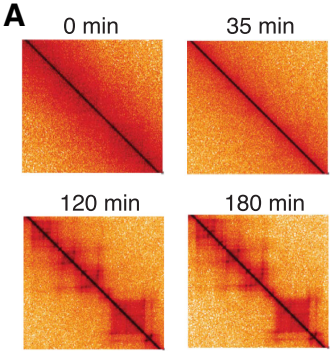

$180 \mathrm{~min}$
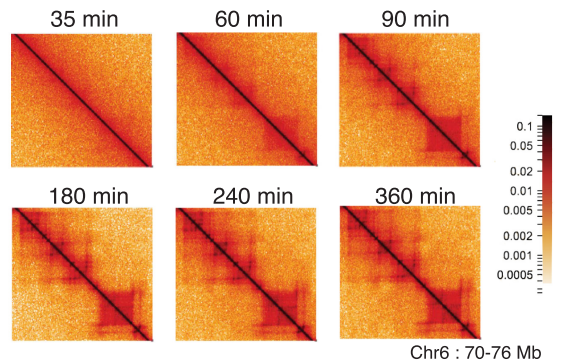

B

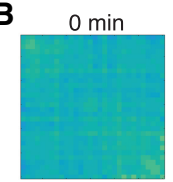

$120 \mathrm{~min}$

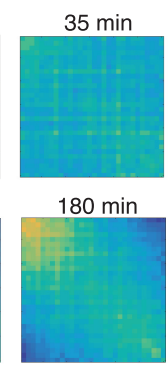

E

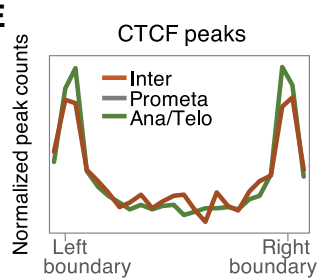

I

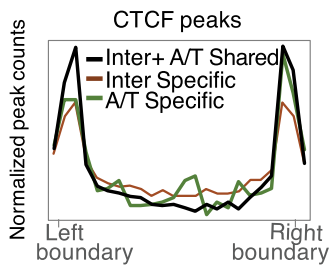

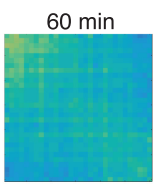
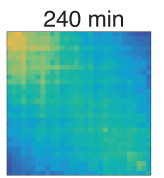

F

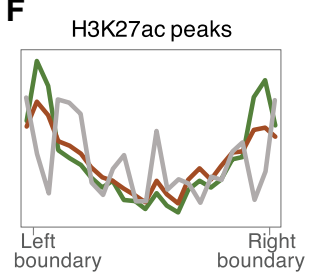

J

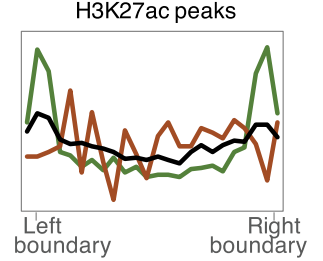

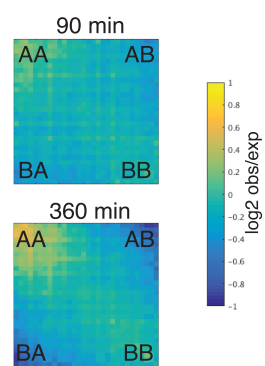

G

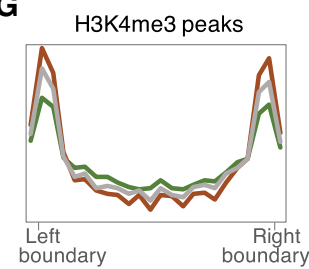

K
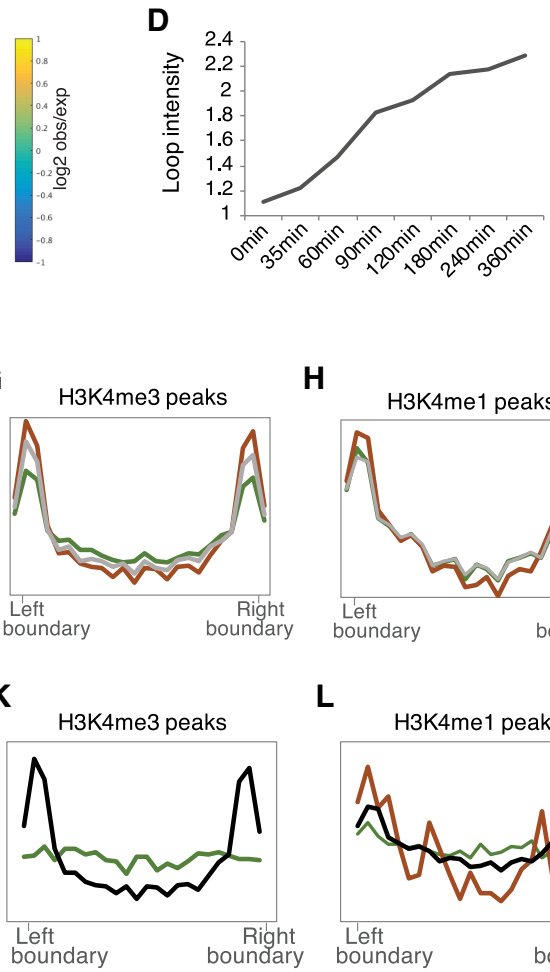

H
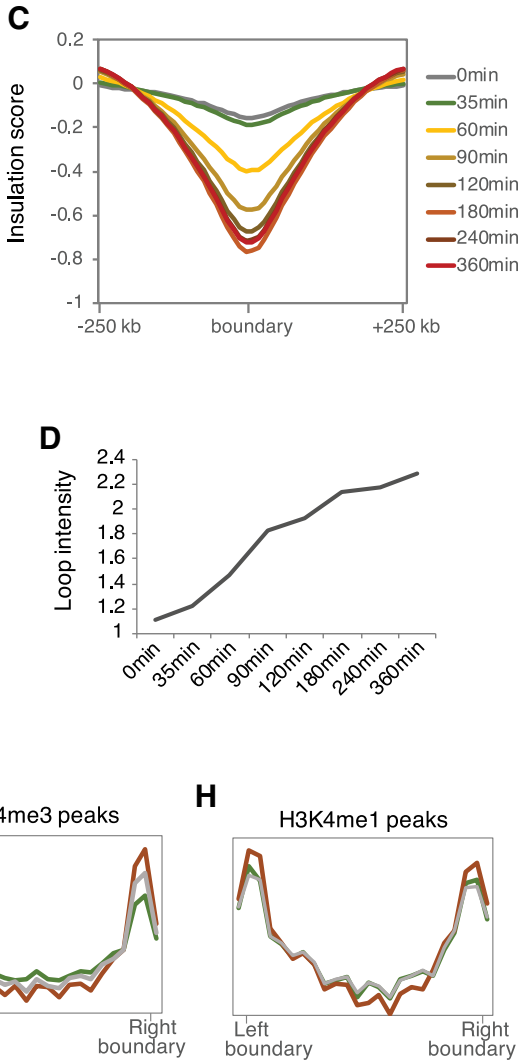

$\mathbf{L}$

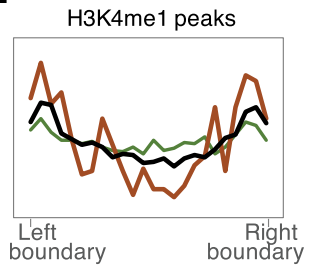

Figure 6. Long-range chromatin interactions are reformed between 90 and 120 min after release from mitotic arrest. (A) Hi-C contact maps of chromosome 6: 70,000,000-76,000,000 showing TADs for each time point. (B) Saddle plots showing global A-A, B-B, and A-B compartment signals for each time point. A/B compartment score derived from first principle components were sorted and divided into 30 quantiles. Saddle plots show the average observed/expected interaction frequency between regions according to the eigen vector values of both ends. $(C)$ Average insulation score near TAD boundaries for each time point. $(D)$ Average DNA loop intensity for each time point. Loop annotations were firstly identified for the 360-min time point using hiccups. The loop intensity is the average observed/expected interaction frequency. $(E-H)$ ChIP-seq signals of CTCF $(E)$, H3K27ac $(F)$, H3K4me3 $(G)$, and H3K4me1 $(H)$ in interphase (orange), prometaphase (gray), and anaphase/telophase (green) at TAD boundary regions. (I-L) Interphase and anaphase/telophase peaks were categorized into either interphase-specific (Inter Specific, orange), anaphase/telophase-specific (A/T Specific, green), or shared between interphase and anaphase/telophase (Inter + A/T Shared, black). CTCF $(I), \mathrm{H} 3 \mathrm{~K} 27 \mathrm{ac}(J), \mathrm{H} 3 \mathrm{~K} 4 \mathrm{me} 3(K)$, and H3K4me1 $(L)$ peaks in each category were aligned at TAD boundary regions. In $K$, there were no $\mathrm{H} 3 \mathrm{~K} 4 \mathrm{me} 3$ interphase-specific peaks that were observed at TAD boundary regions.

blot analyses showed that CTCF is largely dispersed to the cytoplasm in prometaphase, then recruited on chromatin in anaphase/telophase (Supplemental Fig. S7A,B). We then analyzed the distribution of CTCF binding peaks at the TAD boundaries in each cell cycle phase. As previously suggested, interphase CTCF binding was enriched at the TAD boundaries. We did not observe any enrichment at the boundaries in prometaphase, possibly due to the limited numbers of binding sites during this stage. Strik- ingly, anaphase/telophase CTCF binding was strongly enriched at the boundaries even higher than that seen in interphase (Fig. 6E). These data indicate that although CTCF is not responsible for "memory" of insulator elements during prometaphase, it may play a role in TAD reformation during anaphase/telophase, particularly by relocalizing at the boundaries.

Given that active histone marks are enriched at the TAD boundaries in the interphase chromatin (Dixon 
et al. 2012) and H3K4me3 and H3K4mel are well retained throughout mitosis at cis-REs (Fig. 2), we hypothesized that H3K4me3 and H3K4me1 may bookmark the TAD boundaries in prometaphase when CTCF is absent. We examined the distribution of histone modification binding sites at the TAD boundaries in interphase, prometaphase, and anaphase/telophase. As expected, mitotic H3K27ac was depleted at the boundaries as reduced in prometaphase (Fig. 6F). Strikingly, however, H3K4me3 and $\mathrm{H} 3 \mathrm{~K} 4 \mathrm{mel}$ were enriched at the boundaries in all cell cycle phases including prometaphase and anaphase/telophase (Fig. 6G,H), suggesting that $\mathrm{H} 3 \mathrm{~K} 4 \mathrm{me} 3$ and $\mathrm{H} 3 \mathrm{~K} 4 \mathrm{me} 1$ act as a bookmark of insulator elements to allow cells to remember where TADs need to be formed after mitosis.

Although CTCF and H3K27ac binding were significantly decreased in prometaphase, $56 \%$ of CTCF $(17,004$ peaks) (Supplemental Fig. S7C) and 79\% of H3K27ac $(35,771$ peaks) (Fig. 1B) interphase binding sites were recovered in anaphase/telophase. Interestingly, we found new binding sites on anaphase/telophase chromatin for CTCF (1728 peaks) and H3K27ac (11,927 peaks). In addition, both CTCF and H3K27ac were strongly enriched at the TAD boundaries, especially in anaphase/telophase (Fig. 6E,F). Thus, we investigated whether CTCF or H3K27ac may have anaphase/telophase-specific function on insulator elements. To this end, peaks were divided into three categories: (1) "shared," observed in both interphase and anaphase/telophase; (2) "interphase-specific," observed only in interphase; and (3) "anaphase/telophase-specific," observed only in anaphase/telophase. When characterizing the distribution of binding peaks in each category at the boundaries, we observed that CTCF "shared" peaks were highest at the boundaries (Fig. 6I), indicating that CTCF is recruited at the boundaries in anaphase/telophase and remains there in the next G1 phase. Conversely, H3K27ac "anaphase/telophase-specific" peaks were greatly enriched at the boundaries, stronger than "shared" peaks, while "interphase-specific" peaks were depleted (Fig. 6J), indicating that enrichment of $\mathrm{H} 3 \mathrm{~K} 27 \mathrm{ac}$ binding at insulators is mostly either newly bound to anaphase/telophase or recovery of interphase binding after prometaphase. We did not observe noticeable enrichment in either $\mathrm{H} 3 \mathrm{~K} 4 \mathrm{me} 3$ or $\mathrm{H} 3 \mathrm{~K} 4 \mathrm{mel}$ "anaphase/ telophase-specific" binding (Fig. 6K,L). Together, these results suggest that the increase in $\mathrm{H} 3 \mathrm{~K} 27 \mathrm{ac}$ binding during anaphase/telophase may contribute to TAD reformation.

\section{Discussion}

Here, we provide a temporal order of genome organization during and after mitosis. During prometaphase, histone methylation binding is largely retained, however only low levels of transcription occur and no long-range chromatin interactions are detected. Because histone modifications are established first, we investigated whether mitotic histone modification binding contributes to gene reactivation or to the formation of long-range chromatin interactions. We observed that levels of $\mathrm{H} 3 \mathrm{~K} 4 \mathrm{me} 3$ and $\mathrm{H} 3 \mathrm{~K} 4 \mathrm{mel}$ are stable throughout mitosis at promoters and enhancers, respectively, and both at insulators. H3K4mel remains at enhancers of cell type-specific genes and TFs binding motifs, which regulate cell type-specific gene expression during prometaphase. This indicates that histone methylations act as a widespread epigenetic memory of regulatory information previously active in the mother cells. Limited H3K27ac remains associated with mitotic chromatin for the accurate transmission of transcription programs and early expression of cell typespecific genes. Loss of $\mathrm{H} 3 \mathrm{~K} 27 \mathrm{ac}$ in prometaphase is recovered in anaphase/telophase preferentially at promoters and insulators. This recovery of $\mathrm{H} 3 \mathrm{~K} 27 \mathrm{ac}$ by anaphase/ telophase is required for gene reactivation and is particularly relocalized at the TAD boundaries. When cells enter cytokinesis, most of the genes are transcribed. Long-range chromatin interactions gradually increase from cytokinesis, and are complete between 90 and 120 min G1. In addition to H3K27ac, CTCF lost in prometaphase is recruited in anaphase/telophase at the TAD boundaries, which may be involved in the reformation of TADs in the daughter cells. Overall, the genome is orderly reformed in which histone methylations are retained throughout mitosis, followed by histone acetylation and CTCF in anaphase/ telophase, transcription in cytokinesis, then long-range interactions in 90 min G1 (Fig. 7).

Consistent with previous reports using different approaches such as quantitative mass spectrometry (Zhiteneva et al. 2017; Ginno et al. 2018; Javasky et al. 2018), our ChIP-seq analysis reveals the global retention of $\mathrm{H} 3 \mathrm{~K} 4 \mathrm{me} 3$ and $\mathrm{H} 3 \mathrm{~K} 4 \mathrm{me} 1$, but reduction in $\mathrm{H} 3 \mathrm{~K} 27 \mathrm{ac}$ during prometaphase. Our spike-in normalized ChIP-seq allows us to study quantitative and spatial changes in histone modifications during the mitosis-G1 transition. This retention of histone modifications has been suggested to function as a bookmark of the transcriptional program during mitosis. Notably, we observed that widespread histone methylations on mitotic chromatin bookmark cis-REs. First, H3K4me3 bookmarks promoters of genes during prometaphase. Ninety-eight percent of promoters retain $\mathrm{H} 3 \mathrm{~K} 4 \mathrm{me} 3$ during prometaphase (Fig. 2A) and mitotic H3K4me3 binding has positive correlations with gene expression (Fig. 4D). However, harboring H3K4me3 does not seem to facilitate rapid transcriptional reactivation because the Pearson correlation between H3K4me3 signals and gene expression is not particularly high in early expressing genes such as 0 -min or 35-min genes, compared with late expressing genes such as 90-min, 120-min, or 180-min genes (Supplemental Fig. S4C). Second, H3K4me1 bookmarks enhancers of cell type-specific genes during prometaphase. Cell type-specific genes tend to contain $\mathrm{H} 3 \mathrm{~K} 4 \mathrm{mel}$ during prometaphase and to be expressed early in the mitosis-G1 transition (Figs. 3A,B, 4H). This may associate with TFs binding such as AP1 family TFs (Long 2012), RUNX2 (Ducy et al. 1997; Komori et al. 1997; Otto et al. 1997), TEADs (Kegelman et al. 2018), or FOXO1 (Rached et al. 2010; Teixeira et al. 2010), which are known to have a crucial role in bone formation or homeostasis. Genome-wide approach remains to be examined to reveal whether these TFs occupy with H3K4me1 during mitosis at cell type-specific enhancers. 


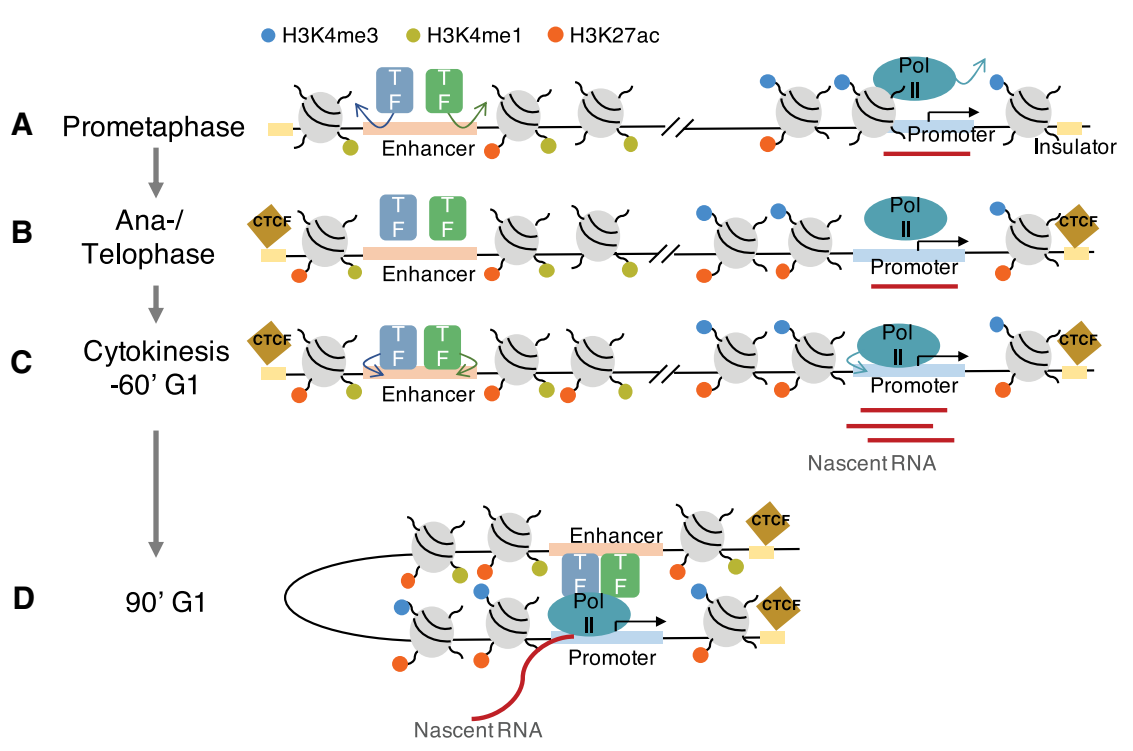

Figure 7. Temporal regulation of genome reorganization by histone modifications, nascent transcription, and long-range chromatin interactions during mitosis-G1. $(A)$ In prometaphase, Pol II and TFs, as well as CTCF, dissociate, although some genes are actively transcribed. H3K27ac is globally lost except for a subset of enhancers of cell type-specific genes and limited promoters of housekeeping genes, while H3K4me3 and $\mathrm{H} 3 \mathrm{~K} 4 \mathrm{me} 1$ are stably bound at promoter and enhancer respectively, and both at insulator. (B) In anaphase/telophase, H3K27ac is recruited back at promoter, enhancer, and insulator. CTCF is also recruited at insulator. (C) In cytokinesis/60-min G1, Pol II and TFs reassociate, and most genes are reactivated. (D) In 90-min G1, longrange chromosomal interactions appear to be reestablished.
Last, H3K4me3 and H3K4me1 bookmark insulators during prometaphase (Fig. 6G,H). Although active histone marks have been well investigated to be enriched at TAD boundaries, the distribution of mitotic histone marks at TADs boundaries has not. Altogether, these data indicate that mitotic $\mathrm{H} 3 \mathrm{~K} 4 \mathrm{me} 3$ and $\mathrm{H} 3 \mathrm{~K} 4 \mathrm{me} 1$ contribute to the faithful establishment of the transcriptional program, epigenetic landscapes, and chromatin architecture across mitosis. Similar to these active histone methylation marks, repressive histone methylation marks, including H3K9me2, H3K9me3, and H3K27me3, are globally maintained during mitosis (Wang and Higgins 2013). A recent study shows that H3K9me2 ensures the inheritance of spatial position at the nuclear periphery throughout mitosis (Poleshko et al. 2019). Thus, these suggest that repressive histone methylation marks likewise would have a role in epigenetic memory of transcriptionally silent genes as well as spatial organization of genome throughout mitosis.

In our ChIP-seq analysis, H3K27ac substantially increases in the number of binding sites and binding signal on anaphase/telophase chromatin (Fig.1B,E). First, this increase may have a role in transcriptional reactivation. A recent study shows that $\mathrm{H} 3 \mathrm{~K} 27$ ac signals during mitotic exit correlate with increased transcriptional activity in early G1 at both promoters and enhancers by measuring Pol II binding in erythroblasts (Hsiung et al. 2016). Our analysis combined with EU-RNA-seq, and with the use of spike-in normalization, reveals that $\mathrm{H} 3 \mathrm{~K} 27 \mathrm{ac}$ in anaphase/telophase, deposited only at promoters but not at enhancers, is also the most predictive histone mark for transcriptional reactivation among the three active histone marks tested in this study (Fig. 4D). Enhancer-promoter loops were lost in mitosis and not formed until cytokinesis at $60 \mathrm{~min}$ (Fig. 6D), which may explain why we did not observe any positive correlations with transcriptional activation at AE regions. Furthermore, A-485-treated H3K27ac inhibition confirmed that $\mathrm{H} 3 \mathrm{~K} 27 \mathrm{ac}$ recovery has a mitotic bookmarking function. Surprisingly, transcriptional activation was perturbed for $\sim 50 \%$ of dysregulated genes by inhibit- ing $\mathrm{H} 3 \mathrm{~K} 27 \mathrm{ac}$ recovery (Fig. 5B), indicating that $\mathrm{H} 3 \mathrm{~K} 27 \mathrm{ac}$ is required for posttranscriptional activation. In addition to transcription, as $\mathrm{H} 3 \mathrm{~K} 27 \mathrm{ac}$ is enriched at the TAD boundaries in interphase chromatin (Dixon et al. 2012), we tested whether the increase of H3K27ac in anaphase/ telophase has a role in the formation of TADs. We found a significant number of new $\mathrm{H} 3 \mathrm{~K} 27 \mathrm{ac}$ binding sites in anaphase/telophase, which are only present in anaphase/telophase (Fig. 1B). Combined with Hi-C data, we surprisingly found that this anaphase/telophase-specific H3K27ac binding was particularly enriched at the TAD boundaries and was even higher than interphase specific peaks (Fig. $6 \mathrm{~J})$, suggesting anaphase/telophase-specific function of $\mathrm{H} 3 \mathrm{~K} 27 \mathrm{ac}$ at insulators. In the future, it would be interesting to determine the functional role of $\mathrm{H} 3 \mathrm{~K} 27 \mathrm{ac}$ in the reformation of long-range interactions after mitosis and whether it serves to recruit architectural proteins CTCF or cohesin complex or/and provide a bookmark for domain boundaries or A-A and B-B compartments. Taken together, the increase of $\mathrm{H} 3 \mathrm{~K} 27 \mathrm{ac}$ in anaphase/telophase seems to influence promoters-driven transcriptional reactivation and TAD reformation.

BRD4 is a histone acetyltransferase (HAT) that acetylates histones $\mathrm{H} 3$ and $\mathrm{H} 4$ such as $\mathrm{H} 3 \mathrm{~K} 14 \mathrm{ac}, \mathrm{H} 3 \mathrm{~K} 27 \mathrm{ac}$, H3K122ac, and H4K16ac (Filippakopoulos et al. 2012; Devaiah et al. 2016). It binds AEs and controls the activation of cell type-specific genes in various cell systems (Lee et al. 2017; Najafova et al. 2017; Wu et al. 2018). Prior studies have shown that BRD4 is partially retained on mitotic chromatin and its overexpression accelerates the transcriptional activation in early G1 (Dey et al. 2009; Zhao et al. 2011), suggesting its function as a transcriptional bookmark on mitotic chromatin. Recently, a genomewide approach reveals that BRD4 widely occupies mitotic chromatin at H3K27ac sites. However, neither transcription activation nor H3K27ac mitotic binding were perturbed by mitotic-specific inhibition of BRD4 following JQ1 treatment (Behera et al. 2019). This suggests that BRD4 is dispensable for either transcriptional reactivation 
or $\mathrm{H} 3 \mathrm{~K} 27 \mathrm{ac}$ retention during mitosis, but BRD4 may still be involved in some other regulatory function. Another recent study shows that BRD4 is indispensable for osteoblast-lineage specification during differentiation. ChIPseq reveals a high co-occupancy of BRD4 with other TFs such as $\mathrm{C} / \mathrm{EBPb}, \mathrm{TEAD} 1$, FOSL2, and JUND at putative osteoblast-specific enhancers in human fetal osteoblasts cells, hFOB (Najafova et al. 2017). We observed that a subset of BRD4 and c-Jun associated with mitotic chromatin using immunofluorescence analysis in U2OS cells (data not shown). Although the colocalization of two TFs and genome-wide spatial information needs to be explored, these observations suggest that mitotic BRD4 may recruit TFs at cell type-specific enhancers and play a role in epigenetic memory of cell type-specific transcriptional program.

Recently, a genome-wide RNA pulse-labeling study showed that some genes are actively transcribed in prometaphase arrested cells, and described waves of gene reactivation during mitotic exit (Palozola et al. 2017). Using the same approach, we were able to observe mitotically expressed genes, as well as the hierarchy of gene activation from prometaphase to G1 phase (Fig. 4). However, we also made a set of different observations. First, while our study reveals that the largest number of genes are first activated at $60 \mathrm{~min}$ (cytokinesis/early G1), the other study shows it at $80 \mathrm{~min}$ (metaphase-anaphase), which is earlier in the cell cycle than our observation. This conflicting result can be explained by the use of different synchronization protocols. Although both studies use thymidinenocodazole block to arrest prometaphase cells, the efficiency of cell cycle synchronization can be affected by incubation time and concentration of chemicals. Long incubation or high concentration of chemicals can prevent the ability of cells exiting mitosis and reentering the next G1 phase, and therefore can delay cells released from mitotic arrest and lead to a wide range of heterogeneous cell populations (Zieve et al. 1980). Thus, we used less nocodazole for shorter incubation time and enabled to efficiently enrich homogenous cell populations at each time point. Second, our analysis reveals that the largest number of cell type-specific genes are expressed at 60 min (cytokinesis/early G1) in a similar trend with general EU-labeled gene expression, yet the other study shows that most are expressed at $300 \mathrm{~min}$ (early G1), which is later than when the largest number of EU-labeled genes are first activated at $80 \mathrm{~min}$. This difference may simply result from low coverage of cell type-specific genes: 113 bone-specific genes in our study and 149 liver-specific genes in their study. However, both studies are in agreement regarding the timing of activation of cell type-specific genes at early G1. Activation of cell type-specific gene expression requires appropriate cell type-specific TFs, which are mostly recruited by cytokinesis, and enhancer-mediated loops, which start to be formed after cytokinesis. Overall, in spite of a few different observations, we were able to find genes actively transcribed throughout mitosis to G1.

Multiple studies show that CTCF remains associated with mitotic chromosomes using imaging and Western blot analyses (Burke et al. 2005; Liu et al. 2017), which provide suggestive mitotic bookmarking function at insulator elements, given its essential role in TAD formation. Our ChIP-seq analysis, however, shows that CTCF binding sites are almost entirely lost during prometaphase. Dissociation of CTCF from mitotic chromatin was also observed using imaging and chromatin fractionation approaches. Phosphorylation of CTCF may explain this dissociation. In vitro assay shows that CTCF becomes highly phosphorylated during mitosis and this phosphorylation of CTCF impairs its DNA-binding activity (Sekiya et al. 2017). A recent study using a different genomic technique, CUT\&RUN, which can be performed on unfixed cells, unlike ChIP-seq, reveals the loss of CTCF binding in prometaphase as well (Oomen et al. 2019). Thus, it seems unlikely that our observation is due to technical artifacts such as formaldehyde-induced fixation. Interestingly, the majority of loss of CTCF binding during prometaphase is regained by anaphase/telophase, earlier than TAD formation, and CTCF relocalizes at the TAD boundaries. Similarly, cohesin almost completely dissociates during prometaphase and rapidly reassociates as cells exit mitosis (Cai et al. 2018; Abramo et al. 2019). The loop extrusion model underlies TAD formation through cohesinmediated loop extrusion, which is stalled at TAD boundaries due to CTCF binding (Sanborn et al. 2015; Fudenberg et al. 2016). Thus, loss of TADs during prometaphase seems to be due to loss of CTCF and cohesin and TAD reformation seems to be mediated by CTCF and cohesin recruitment at the boundaries during anaphase/telophase.

\begin{abstract}
Materials and methods
Cell culture and cell cycle synchronization

U2OS cells were cultured in DMEM (Gibco) and 10\% FBS. RPE1 cells were cultured in DMEM-F12 (Gibco) and 10\% FBS. Cells were incubated at $37^{\circ} \mathrm{C}$ and $5 \% \mathrm{CO}_{2}$. Cells were synchronized using thymidine and nocodazole treatments. The mitotic cells were collected by mitotic shakeoff. A-485 (10 $\mu \mathrm{M}$; Tocris) was used to inhibit H3K27ac levels. See the Supplemental Material for detailed description.
\end{abstract}

\section{Immunofluorescence}

Cells were grown on glass coverslips and fixed with $4 \%$ paraformaldehyde in PBS for 5 min at room temperature. Fixed cells were permeabilized with cold PBS containing $0.5 \%$ Triton X100 for 5 min. Cells were blocked with $1 \%$ BSA in PBS for $1 \mathrm{~h}$ at room temperature and incubated in primary antibody in blocking buffer overnight at $4^{\circ} \mathrm{C}$, followed by secondary antibody for $1 \mathrm{~h}$ at room temperature. Cells were then briefly stained with $1 \mu \mathrm{g} / \mathrm{mL}$ Hoechst 33342 (Molecular Probes H-1399) in PBS and mounted in VectaShield (Vector Laboratories). Images were acquired in a Zeiss LSM710 confocal microscope. Images were analyzed and prepared for presentation in Photoshop.

\section{Isolation of nuclear and cytoplasmic fractions}

Cells were resuspended in hypotonic buffer (5 mM Pipes at $\mathrm{pH} 8$, $85 \mathrm{mM} \mathrm{KCl}, 0.5 \% \mathrm{NP}-40$, protease inhibitor) for $10 \mathrm{~min}$ on ice, followed by centrifugation at $500 \mathrm{~g}$ for $10 \mathrm{~min}$ at $4^{\circ} \mathrm{C}$. The 
supernatant containing the cytoplasmic fraction was transferred and saved. The pellet was resuspended in lysis buffer $150 \mathrm{mM}$ Hepes at $\mathrm{pH} 7.9,5 \mathrm{mM} \mathrm{MgCl}_{2}, 0.2 \%$ Triton X-100, 20\% glycerol, $300 \mathrm{mM} \mathrm{NaCl}$, protease inhibitor) for $30 \mathrm{~min}$ on ice, followed by centrifugation at $12,000 \mathrm{~g}$ for $20 \mathrm{~min}$ at $4^{\circ} \mathrm{C}$. The supernatant was collected as the nuclear fraction.

Histone isolation and Western blotting

For histone extraction, the protocol is adapted from previous work (Shechter et al. 2007). Briefly, following nuclei isolation, soluble histones were extracted with $0.2 \mathrm{M} \mathrm{HCl}$, followed by TCA/acetone precipitation. For Western blot analysis, protein samples were resolved in SDS-PAGE gels and transferred to PVDF membranes (Millipore). Membranes were blocked with $5 \%$ milk in TBST $(0.25 \%$ Tween $20,20 \mathrm{mM}$ Tris at $\mathrm{pH} 8.0$, $137 \mathrm{mM} \mathrm{NaCl}$ ) and incubated with primary antibody overnight at $4^{\circ} \mathrm{C}$. After three 5 -min washes in TBST, HRP-conjugated secondary antibody was added for $1 \mathrm{~h}$ at room temperature. Membranes were visualized by SuperSignal West Pico or Femto (Thermo Fisher Scientific) reagent.

\section{Antibodies}

The following antibodies were purchased from the indicated commercial sources: anti-H3K4me3 (Abcam ab8580), anti-H3K4me1 (Abcam ab8895), anti-H3K27ac (Abcam ab4729), anti-CTCF (Active Motif 61311), anti-spike-in (Active Motif 61686), anti- $\alpha$-Tubulin (Sigma T5168), anti-Histone H3 (Cell Signaling 4499), and anti-H3S10p (Cell Signaling 3377).

\section{ChIP-seq}

Cells $\left(5 \times 10^{6}\right)$ were cross-linked with $1 \%$ formaldehyde for $10 \mathrm{~min}$, and ChIP-seq was performed as described previously (Toyama et al. 2019). Spike-in was carried out according to vendor protocols (Active Motif). Briefly, $50 \mathrm{ng}$ of spike-in chromatin (Active Motif 53083 ) was added to $25 \mu \mathrm{g}$ of U2OS or RPE1 chromatin to incubate with $2 \mu$ g of spike-in antibody together with $5 \mu$ g of anti-H3K4me3, anti-H3K4me1, anti-H3K27ac, or anti-CTCF antibodies. DNA libraries were generated using the Kapa Hyper preparation kit for Illumina platforms (Kapa Biosystems). Libraries were sequenced in a NextSeq 500 system (Illumina). See the Supplemental Material for detailed information about data analysis, including alignment, normalization, peak calling, cis-REs identification, motif analysis, and Pearson correlation coefficient test.

\section{Spike-in control sequences and EU-RNA-seq}

Biotinylated spike-in controls and samples for EU-RNA-seq were prepared as previously described (Palozola et al. 2017). Briefly, U2OS cells were pulse-labeled with $0.5 \mathrm{mM}$ EU for $35 \mathrm{~min}$ at $37^{\circ} \mathrm{C}$. Total RNA was harvested using Trizol (Ambion) and purified using miRNeasy (Qiagen). Click reaction was performed to conjugate biotin to the EU-labeled RNA using Click-iT nascent RNA capture kit (Invitrogen). Two biotinylated spike-in control RNAs were added to $1.5 \mu \mathrm{g}$ of each biotinylated sample $(0.36 \mathrm{ng}$ of control \#1 and $0.036 \mathrm{ng}$ of control \#2). Biotin-EU-RNAs, including spike-in controls, were pulled down with streptavidin-coated magnetic beads. For validation of biotin-RNA spike-in controls, cDNA was generated using the SuperScript VILO cDNA synthesis kit (Invitrogen) followed by qPCR. For sequencing, cDNA libraries were generated using the Ovation human FFPE RNAseq multiplex system. Multiplexed pair-end sequencing was performed on a NextSeq 500 instrument (Illumina). See the Supple- mental Material for detailed information about data analysis, including alignment, normalization, identification of hierarchy of gene expression, and GO enrichment analysis.

Hi-C

$\mathrm{Hi}-\mathrm{C}$ was performed using the in situ method as previously described (Rao et al. 2014). Briefly, U2OS cells $\left(2 \times 10^{6}\right)$ were crosslinked with formaldehyde. Chromatin was digested with a restriction enzyme MboI (NEB), biotinylated with biotin-ATP (Life Technologies), and then ligated with T4 DNA ligase (NEB). DNA was purified and sheared with Covaris LE220 instrument (Covaris). Biotinylated DNA interactions were pulled down with Dynabeads MyOne Streptavin T1 Beads (Life Technologies) and sequenced in a NovaSeq 6000 sequencing system (Illumina). See the Supplemental Material for detailed information about data analysis.

\section{Accession numbers}

The Gene Expression Omnibus accession number for the ChIPseq, EU-RNA-seq, and $\mathrm{Hi}-\mathrm{C}$ data reported in this study is GSE141139.

\section{Acknowledgments}

We thank members of the Hetzer laboratory for critical reading of the manuscript. This work is supported by the National Institutes of Health (NIH) Transformative Research Award grants R01 NS096786, R01 GM126829, and DP5 OD023071; the Keck Foundation; and the NOMIS Foundation. This work is also supported by the Waitt Advanced Biophotonics Core Facility of Salk Institute with funding from NIH National Cancer Institute (NCI) Cancer Center Support Grant (CCSG) P30 014195 and the Waitt Foundation; the Next-Generation Sequencing Core Facility and the Razavi Newman Integrative Genomics and Bioinformatics Core Facility of the Salk Institute with funding from NIH NCI CCSG P30 014195, the Chapman Foundation, and the Helmsley Charitable Trust; the Flow Cytometry Core Facility of the Salk Institute with funding from NIH NCI CCSG P30 014195; and the Mass Spectrometry Core of the Salk Institute with funding from NIH NCI CCSG P30 014195 and the Helmsley Center for Genomic Medicine.

Author contributions: M.W.H. and H.K. designed the experiments and wrote the manuscript. H.K. established cell synchronization protocols, performed synchronized time courses, performed imaging, Western blot, ChIP-seq, and EU-RNA-seq analyses. M.N.S. and H.K. analyzed the ChIP-seq and EU-RNAseq data. J.R.D., Z.X., and S.C. conducted the Hi-C experiment. J.R.D. and Z.X. analyzed the Hi-C data.

\section{References}

Abramo K, Valton AL, Venev SV, Ozadam H, Fox AN, Dekker J. 2019. A chromosome folding intermediate at the condensinto-cohesin transition during telophase. Nat Cell Biol 21: 1393-1402. doi:10.1038/s41556-019-0406-2

Behera V, Stonestrom AJ, Hamagami N, Hsiung CC, Keller CA, Giardine B, Sidoli S, Yuan ZF, Bhanu NV, Werner MT, et al. 2019. Interrogating histone acetylation and BRD4 as mitotic bookmarks of transcription. Cell Rep 27: 400-415.e5. doi:10 .1016/j.celrep.2019.03.057

Bozec A, Bakiri L, Jimenez M, Schinke T, Amling M, Wagner EF. 2010. Fra-2/AP-1 controls bone formation by regulating 
osteoblast differentiation and collagen production. J Cell Biol 190: $1093-1106$. doi:10.1083/jcb.201002111

Burke LJ, Zhang R, Bartkuhn M, Tiwari VK, Tavoosidana G, Kurukuti S, Weth C, Leers J, Galjart N, Ohlsson R, et al. 2005. CTCF binding and higher order chromatin structure of the H19 locus are maintained in mitotic chromatin. EMBO $J$ 24: 3291-3300. doi:10.1038/sj.emboj.7600793

Cai Y, Hossain MJ, Hériché JK, Politi AZ, Walther N, Koch B, Wachsmuth M, Nijmeijer B, Kueblbeck M, Martinic-Kavur $M$, et al. 2018. Experimental and computational framework for a dynamic protein atlas of human cell division. Nature 561: 411-415. doi:10.1038/s41586-018-0518-z

Calo E, Wysocka J. 2013. Modification of enhancer chromatin: what, how, and why? Mol Cell 49: 825-837. doi:10.1016/j .molcel.2013.01.038

Caravaca JM, Donahue G, Becker JS, He X, Vinson C, Zaret KS. 2013. Bookmarking by specific and nonspecific binding of FoxAl pioneer factor to mitotic chromosomes. Genes DeV 27: 251-260. doi:10.1101/gad.206458.112

Chapurlat RD, Confavreux CB. 2016. Novel biological markers of bone: from bone metabolism to bone physiology. Rheumatology (Oxford) 55: 1714-1725. doi:10.1093/rheumatology/ kev410

Creyghton MP, Cheng AW, Welstead GG, Kooistra T, Carey BW, Steine EJ, Hanna J, Lodato MA, Frampton GM, Sharp PA, et al. 2010. Histone H3K27ac separates active from poised enhancers and predicts developmental state. Proc Natl Acad Sci 107: 21931-21936. doi:10.1073/pnas.1016071107

Deluz C, Friman ET, Strebinger D, Benke A, Raccaud M, Callegari A, Leleu M, Manley S, Suter DM. 2016. A role for mitotic bookmarking of SOX2 in pluripotency and differentiation. Genes Dev 30: 2538-2550. doi:10.1101/gad.289256.116

Devaiah BN, Case-Borden C, Gegonne A, Hsu CH, Chen Q, Meerzaman D, Dey A, Ozato K, Singer DS. 2016. BRD4 is a histone acetyltransferase that evicts nucleosomes from chromatin. Nat Struct Mol Biol 23: 540-548. doi:10.1038/nsmb.3228

Dey A, Nishiyama A, Karpova T, McNally J, Ozato K. 2009. Brd4 marks select genes on mitotic chromatin and directs postmitotic transcription. Mol Biol Cell 20: 4899-4909. doi:10.1091/ mbc.e09-05-0380

Dileep V, Ay F, Sima J, Vera DL, Noble WS, Gilbert DM. 2015. Topologically associating domains and their long-range contacts are established during early G1 coincident with the establishment of the replication-timing program. Genome Res 25: 1104-1113. doi:10.1101/gr.183699.114

Dixon JR, Selvaraj S, Yue F, Kim A, Li Y, Shen Y, Hu M, Liu JS, Ren B. 2012. Topological domains in mammalian genomes identified by analysis of chromatin interactions. Nature 485: 376-380. doi:10.1038/nature11082

Ducy P, Zhang R, Geoffroy V, Ridall AL, Karsenty G. 1997. Osf2/ Cbfa1: a transcriptional activator of osteoblast differentiation. Cell 89: 747-754. doi:10.1016/S0092-8674|00|80257-3

Egan B, Yuan CC, Craske ML, Labhart P, Guler GD, Arnott D, Maile TM, Busby J, Henry C, Kelly TK, et al. 2016. An alternative approach to ChIP-Seq normalization enables detection of genome-wide changes in histone $\mathrm{H} 3$ lysine 27 trimethylation upon EZH2 inhibition. PLoS One 11: e0166438. doi:10.1371/ journal.pone.0166438

Festuccia N, Dubois A, Vandormael-Pournin S, Gallego Tejeda E, Mouren A, Bessonnard S, Mueller F, Proux C, Cohen-Tannoudji M, Navarro P. 2016. Mitotic binding of Esrrb marks key regulatory regions of the pluripotency network. Nat Cell Biol 18: 1139-1148. doi:10.1038/ncb3418

Filippakopoulos P, Picaud S, Mangos M, Keates T, Lambert JP, Barsyte-Lovejoy D, Felletar I, Volkmer R, Müller S, Pawson
T, et al. 2012. Histone recognition and large-scale structural analysis of the human bromodomain family. Cell 149: 214231. doi:10.1016/j.cell.2012.02.013

Fudenberg G, Imakaev M, Lu C, Goloborodko A, Abdennur N, Mirny LA. 2016. Formation of chromosomal domains by loop extrusion. Cell Rep 15: 2038-2049. doi:10.1016/j.celrep .2016 .04 .085

Gibcus JH, Samejima K, Goloborodko A, Samejima I, Naumova N, Nuebler J, Kanemaki MT, Xie L, Paulson JR, Earnshaw WC, et al. 2018. A pathway for mitotic chromosome formation. Science 359: eaao6135. doi:10.1126/science.aao6135

Ginno PA, Burger L, Seebacher J, Iesmantavicius V, Schübeler D. 2018. Cell cycle-resolved chromatin proteomics reveals the extent of mitotic preservation of the genomic regulatory landscape. Nat Commun 9: 4048. doi:10.1038/s41467-01806007-5

Gottesfeld JM, Forbes DJ. 1997. Mitotic repression of the transcriptional machinery. Trends Biochem Sci 22: 197-202. doi:10.1016/S0968-0004(97)01045-1

Heintzman ND, Stuart RK, Hon G, Fu Y, Ching CW, Hawkins RD, Barrera LO, Van Calcar S, Qu C, Ching KA, et al. 2007. Distinct and predictive chromatin signatures of transcriptional promoters and enhancers in the human genome. Nat Genet 39: 311-318. doi:10.1038/ng1966

Heintzman ND, Hon GC, Hawkins RD, Kheradpour P, Stark A, Harp LF, Ye Z, Lee LK, Stuart RK, Ching CW, et al. 2009. Histone modifications at human enhancers reflect global celltype-specific gene expression. Nature 459: 108-112. doi:10 $.1038 /$ nature07829

Hsiung CC, Morrissey CS, Udugama M, Frank CL, Keller CA, Baek S, Giardine B, Crawford GE, Sung MH, Hardison RC, et al. 2015. Genome accessibility is widely preserved and locally modulated during mitosis. Genome Res 25: 213-225. doi:10.1101/gr.180646.114

Hsiung CC, Bartman CR, Huang P, Ginart P, Stonestrom AJ, Keller CA, Face C, Jahn KS, Evans P, Sankaranarayanan L, et al. 2016. A hyperactive transcriptional state marks genome reactivation at the mitosis-G1 transition. Genes Dev 30: 14231439. doi:10.1101/gad.280859.116

Javasky E, Shamir I, Gandhi S, Egri S, Sandler O, Rothbart SB, Kaplan N, Jaffe JD, Goren A, Simon I. 2018. Study of mitotic chromatin supports a model of bookmarking by histone modifications and reveals nucleosome deposition patterns. Genome Res 28: 1455-1466. doi:10.1101/gr.230300.117

Jochum W, David JP, Elliott C, Wutz A, Plenk H, Matsuo K, Wagner EF. 2000. Increased bone formation and osteosclerosis in mice overexpressing the transcription factor Fra-1. Nat Med 6: 980-984. doi:10.1038/79676

Kadauke S, Udugama MI, Pawlicki JM, Achtman JC, Jain DP, Cheng Y, Hardison RC, Blobel GA. 2012. Tissue-specific mitotic bookmarking by hematopoietic transcription factor GATA1. Cell 150: 725-737. doi:10.1016/j.cell.2012.06.038

Kegelman CD, Mason DE, Dawahare JH, Horan DJ, Vigil GD, Howard SS, Robling AG, Bellido TM, Boerckel JD. 2018. Skeletal cell YAP and TAZ combinatorially promote bone development. FASEB J 32: 2706-2721. doi:10.1096/fj.201700872R

Kirkham GR, Cartmell SH. 2007. Genes and proteins involved in the regulation of osteogenesis. In Topics in Tissue Engineering (ed. N Ashammaki, et al.), pp. 1-22. University of Oulu, Oulu.

Komori T. 2005. Regulation of skeletal development by the Runx family of transcription factors. J Cell Biochem 95: 445-453. doi:10.1002/jcb.20420

Komori T, Yagi H, Nomura S, Yamaguchi A, Sasaki K, Deguchi K, Shimizu Y, Bronson RT, Gao YH, Inada M, et al. 1997. Targeted disruption of Cbfal results in a complete lack of bone 
formation owing to maturational arrest of osteoblasts. Cell 89: 755-764. doi:10.1016/S0092-8674(00)80258-5

Kouskouti A, Talianidis I. 2005. Histone modifications defining active genes persist after transcriptional and mitotic inactivation. EMBO / 24: 347-357. doi:10.1038/sj.emboj.7600516

Kveiborg M, Sabatakos G, Chiusaroli R, Wu M, Philbrick WM, Horne WC, Baron R. 2004. $\triangle$ FosB induces osteosclerosis and decreases adipogenesis by two independent cell-autonomous mechanisms. Mol Cell Biol 24: 2820-2830. doi:10.1128/ MCB.24.7.2820-2830.2004

Lasko LM, Jakob CG, Edalji RP, Qiu W, Montgomery D, Digiammarino EL, Hansen TM, Risi RM, Frey R, Manaves V, et al. 2017. Discovery of a selective catalytic p300/CBP inhibitor that targets lineage-specific tumours. Nature 550: 128-132. doi:10.1038/nature24028

Lee JE, Park YK, Park S, Jang Y, Waring N, Dey A, Ozato K, Lai B, Peng W, Ge K. 2017. Brd4 binds to active enhancers to control cell identity gene induction in adipogenesis and myogenesis. Nat Commun 8: 2217. doi:10.1038/s41467-017-02403-5

Liang K, Woodfin AR, Slaughter BD, Unruh JR, Box AC, Rickels RA, Gao X, Haug JS, Jaspersen SL, Shilatifard A. 2015. Mitotic transcriptional activation: clearance of actively engaged Pol II via transcriptional elongation control in mitosis. Mol Cell 60: 435-445. doi:10.1016/j.molcel.2015.09.021

Liu X, Yu X, Zack DJ, Zhu H, Qian J. 2008. TiGER: a database for tissue-specific gene expression and regulation. BMC Bioinformatics 9: 271. doi:10.1186/1471-2105-9-271

Liu Y, Pelham-Webb B, Di Giammartino DC, Li J, Kim D, Kita K, Saiz N, Garg V, Doane A, Giannakakou P, et al. 2017. Widespread mitotic bookmarking by histone marks and transcription factors in pluripotent stem cells. Cell Rep 19: 12831293. doi:10.1016/j.celrep.2017.04.067

Long F. 2012. Building strong bones: molecular regulation of the osteoblast lineage. Nat Rev Mol Cell Biol 13: 27-38. doi:10 $.1038 / \mathrm{nrm} 3254$

Martínez-Balbás MA, Dey A, Rabindran SK, Ozato K, Wu C. 1995. Displacement of sequence-specific transcription factors from mitotic chromatin. Cell 83: 29-38. doi:10.1016/0092-8674 (95)90231-7

McLean CY, Bristor D, Hiller M, Clarke SL, Schaar BT, Lowe CB, Wenger AM, Bejerano G. 2010. GREAT improves functional interpretation of cis-regulatory regions. Nat Biotechnol 28: 495-501. doi:10.1038/nbt.1630

Muramoto T, Müller I, Thomas G, Melvin A, Chubb JR. 2010. Methylation of H3K4 Is required for inheritance of active transcriptional states. Curr Biol 20: 397-406. doi:10.1016/j.cub .2010.01.017

Nagano T, Lubling Y, Várnai C, Dudley C, Leung W, Baran Y, Mendelson Cohen N, Wingett S, Fraser P, Tanay A. 2017. Cell-cycle dynamics of chromosomal organization at singlecell resolution. Nature 547: 61-67. doi:10.1038/nature23001

Najafova Z, Tirado-Magallanes R, Subramaniam M, Hossan T, Schmidt G, Nagarajan S, Baumgart SJ, Mishra VK, Bedi U, Hesse E, et al. 2017. BRD4 localization to lineage-specific enhancers is associated with a distinct transcription factor repertoire. Nucleic Acids Res 45: 127-141. doi:10.1093/nar/ gkw826

Naumova N, Imakaev M, Fudenberg G, Zhan Y, Lajoie BR, Mirny LA, Dekker J. 2013. Organization of the mitotic chromosome. Science 342: 948-953. doi:10.1126/science.1236083

Nora EP, Lajoie BR, Schulz EG, Giorgetti L, Okamoto I, Servant N, Piolot T, van Berkum NL, Meisig J, Sedat J, et al. 2012. Spatial partitioning of the regulatory landscape of the X-inactivation centre. Nature 485: 381-385. doi:10.1038/nature11049
Nora EP, Goloborodko A, Valton AL, Gibcus JH, Uebersohn A, Abdennur N, Dekker J, Mirny LA, Bruneau BG. 2017. Targeted degradation of CTCF decouples local insulation of chromosome domains from genomic compartmentalization. Cell 169: 930-944.e22. doi:10.1016/j.cell.2017.05.004

Oomen ME, Hansen AS, Liu Y, Darzacq X, Dekker J. 2019. CTCF sites display cell cycle-dependent dynamics in factor binding and nucleosome positioning. Genome Res 29: 236-249. doi:10.1101/gr.241547.118

Orlando DA, Chen MW, Brown VE, Solanki S, Choi YJ, Olson ER, Fritz CC, Bradner JE, Guenther MG. 2014. Quantitative ChIPSeq normalization reveals global modulation of the epigenome. Cell Rep 9: 1163-1170. doi:10.1016/j.celrep.2014.10.018

Otto F, Thornell AP, Crompton T, Denzel A, Gilmour KC, Rosewell IR, Stamp GW, Beddington RS, Mundlos S, Olsen BR, et al. 1997. Cbfal, a candidate gene for cleidocranial dysplasia syndrome, is essential for osteoblast differentiation and bone development. Cell 89: 765-771. doi:10.1016/S0092-8674(00) 80259-7

Palozola KC, Donahue G, Liu H, Grant GR, Becker JS, Cote A, Yu H, Raj A, Zaret KS. 2017. Mitotic transcription and waves of gene reactivation during mitotic exit. Science 358: 119-122. doi:10.1126/science.aal4671

Poleshko A, Smith CL, Nguyen SC, Sivaramakrishnan P, Wong KG, Murray JI, Lakadamyali M, Joyce EF, Jain R, Epstein JA. 2019. H3K9me2 orchestrates inheritance of spatial positioning of peripheral heterochromatin through mitosis. Elife 8: e49278. doi:10.7554/eLife.49278

Prasanth KV, Sacco-Bubulya PA, Prasanth SG, Spector DL. 2003. Sequential entry of components of gene expression machinery into daughter nuclei. Mol Biol Cell 14: 1043-1057. doi:10 $.1091 / \mathrm{mbc} . \mathrm{e} 02-10-0669$

Prescott DM, Bender MA. 1962. Synthesis of RNA and protein during mitosis in mammalian tissue culture cells. Exp Cell Res 26: 260-268. doi:10.1016/0014-4827(62)90176-3

Rached MT, Kode A, Xu L, Yoshikawa Y, Paik JH, Depinho RA, Kousteni S. 2010. FoxO1 is a positive regulator of bone formation by favoring protein synthesis and resistance to oxidative stress in osteoblasts. Cell Metab 11: 147-160. doi:10.1016/j .cmet.2010.01.001

Rao SS, Huntley MH, Durand NC, Stamenova EK, Bochkov ID, Robinson JT, Sanborn AL, Machol I, Omer AD, Lander ES, et al. 2014. A 3D map of the human genome at kilobase resolution reveals principles of chromatin looping. Cell 159: 1665 1680. doi:10.1016/j.cell.2014.11.021

Rutkovskiy A, Stensløkken KO, Vaage IJ. 2016. Osteoblast differentiation at a glance. Med Sci Monit Basic Res 22: 95-106. doi:10.12659/MSMBR.901142

Sabatakos G, Sims NA, Chen J, Aoki K, Kelz MB, Amling M, Bouali Y, Mukhopadhyay K, Ford K, Nestler EJ, et al. 2000. Overexpression of $\Delta \mathrm{FosB}$ transcription factor(s) increases bone formation and inhibits adipogenesis. Nat Med 6: 985 990. doi:10.1038/79683

Sanborn AL, Rao SS, Huang SC, Durand NC, Huntley MH, Jewett AI, Bochkov ID, Chinnappan D, Cutkosky A, Li J, et al. 2015. Chromatin extrusion explains key features of loop and domain formation in wild-type and engineered genomes. Proc Natl Acad Sci 112: E6456-E6465. doi:10.1073/pnas.1518552112

Sekiya T, Murano K, Kato K, Kawaguchi A, Nagata K. 2017. Mitotic phosphorylation of CCCTC-binding factor (CTCF) reduces its DNA binding activity. FEBS Open Bio 7: 397-404. doi:10.1002/2211-5463.12189

Shechter D, Dormann HL, Allis CD, Hake SB. 2007. Extraction, purification and analysis of histones. Nat Protoc 2: 14451457. doi: $10.1038 /$ nprot.2007.202 
Teixeira CC, Liu Y, Thant LM, Pang J, Palmer G, Alikhani M. 2010. Foxo1, a novel regulator of osteoblast differentiation and skeletogenesis. I Biol Chem 285: 31055-31065. doi:10 $.1074 /$ jbc.M109.079962

Teves SS, An L, Hansen AS, Xie L, Darzacq X, Tjian R. 2016. A dynamic mode of mitotic bookmarking by transcription factors. Elife 5: e22280. doi:10.7554/eLife.22280

Toyama BH, Arrojo e Drigo R, Lev-Ram V, Ramachandra R, Deerinck TJ, Lechene C, Ellisman MH, Hetzer MW. 2019. Visualization of long-lived proteins reveals age mosaicism within nuclei of postmitotic cells. J Cell Biol 218: 433-444. doi:10 $.1083 /$ jcb. 201809123

Vagnarelli P. 2013. Chromatin reorganization through mitosis. Adv Protein Chem Struct Biol 90: 179-224. doi:10.1016/ B978-0-12-410523-2.00006-7

Valls E, Sánchez-Molina S, Martínez-Balbás MA. 2005. Role of histone modifications in marking and activating genes through mitosis. I Biol Chem 280: 42592-42600. doi:10 .1074/jbc.M507407200

Vietri Rudan M, Barrington C, Henderson S, Ernst C, Odom DT, Tanay A, Hadjur S. 2015. Comparative Hi-C reveals that CTCF underlies evolution of chromosomal domain architecture. Cell Rep 10: 1297-1309. doi:10.1016/j.celrep.2015.02.004

Wang F, Higgins JM. 2013. Histone modifications and mitosis: countermarks, landmarks, and bookmarks. Trends Cell Biol 23: 175-184. doi:10.1016/j.tcb.2012.11.005
Wu T, Kamikawa YF, Donohoe ME. 2018. Brd4's bromodomains mediate histone $\mathrm{H} 3$ acetylation and chromatin remodeling in pluripotent cells through P300 and Brg1. Cell Rep 25: 17561771. doi:10.1016/j.celrep.2018.10.003

Young DW, Hassan MQ, Yang XQ, Galindo M, Javed A, Zaidi SK, Furcinitti P, Lapointe D, Montecino M, Lian JB, et al. 2007. Mitotic retention of gene expression patterns by the cell fate-determining transcription factor Runx2. Proc Nat1 Acad Sci 104: 3189-3194. doi:10.1073/pnas.0611419104

Zhang Z, Zhang Y, Xiao H, Liang X, Sun D, Peng S. 2012. A gene expression profile of the developing human retinal pigment epithelium. Mol Vis 18: 2961-2975.

Zhao R, Nakamura T, Fu Y, Lazar Z, Spector DL. 2011. Gene bookmarking accelerates the kinetics of post-mitotic transcriptional re-activation. Nat Cell Biol 13: 1295-1304. doi:10 $.1038 /$ ncb2341

Zhiteneva A, Bonfiglio JI, Makarov A, Colby T, Vagnarelli P, Schirmer EC, Matic I, Earnshaw WC. 2017. Mitotic posttranslational modifications of histones promote chromatin compaction in vitro. Open Biol 7: 170076. doi:10.1098/rsob .170076

Zieve GW, Turnbull D, Mullins JM, McIntosh JR. 1980. Production of large numbers of mitotic mammalian cells by use of the reversible microtubule inhibitor nocodazole. Nocodazole accumulated mitotic cells. Exp Cell Res 126: 397-405. doi:10 $.1016 / 0014-4827 / 80 / 90279-7$ 


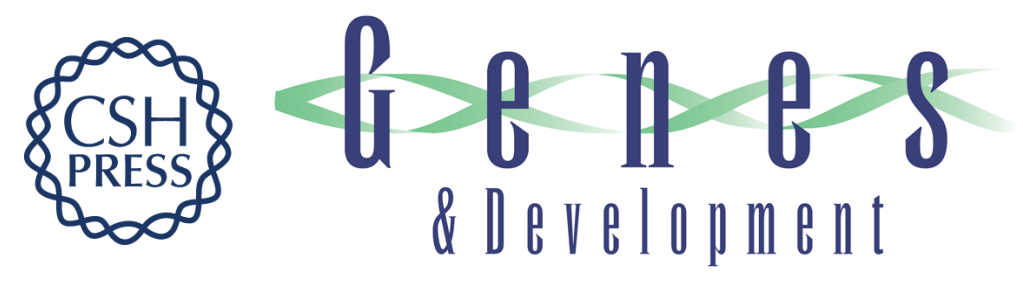

\section{Dynamic regulation of histone modifications and long-range chromosomal interactions during postmitotic transcriptional reactivation}

Hyeseon Kang, Maxim N. Shokhirev, Zhichao Xu, et al.

Genes Dev. 2020, 34: originally published online June 4, 2020

Access the most recent version at doi:10.1101/gad.335794.119

Supplemental Material

References

Creative

Commons

License

Email Alerting

Service
http://genesdev.cshlp.org/content/suppl/2020/06/02/gad.335794.119.DC1

This article cites 75 articles, 21 of which can be accessed free at: http://genesdev.cshlp.org/content/34/13-14/913.full.html\#ref-list-1

This article, published in Genes \& Development, is available under a Creative Commons License (Attribution 4.0 International), as described at http://creativecommons.org/licenses/by/4.0/.

Receive free email alerts when new articles cite this article - sign up in the box at the top right corner of the article or click here.

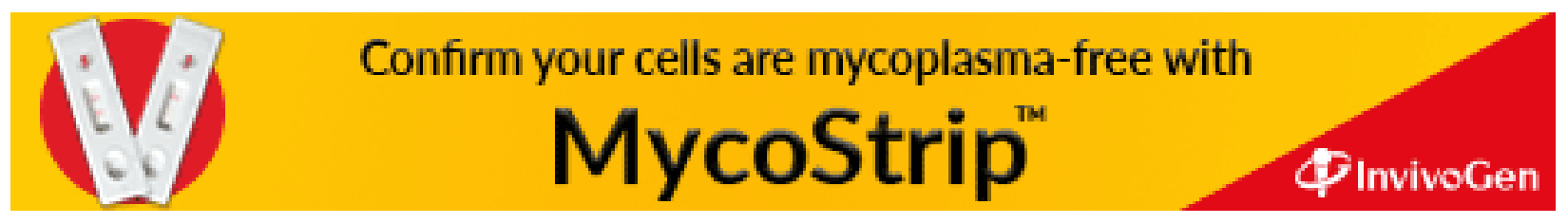

